\title{
Aberrant repair initiated by the adenine-DNA glycosylase does not play a role in UV-induced mutagenesis in Escherichia coli.
}

\author{
Caroline Zutterling ${ }^{1}$, Aibek Mursalimov ${ }^{2}$, Ibtissam Talhaoui ${ }^{3}$, Zhanat Koshenov ${ }^{2}$, Zhiger Akishev ${ }^{4}$,

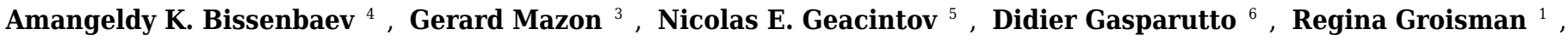 \\ Dmitry O. Zharkov ${ }^{7,8}$, Bakhyt T. Matkarimov ${ }^{2}$, Murat Saparbaev ${ }^{\text {Corresp. } 1}$

Background. DNA repair is essential to counteract damage to DNA induced by endo- and exogenous factors, to maintain genome stability. However, challenges to the faithful discrimination between damaged and non-damaged DNA strands do exist, such as mismatched pairs between two regular bases resulting from spontaneous deamination of 5-methylcytosine or DNA polymerase errors during replication. To counteract these mutagenic threats to genome stability, cells evolved the mismatch-specific DNA glycosylases that can recognize and remove regular DNA bases in the mismatched DNA duplexes. The Escherichia coli adenine-DNA glycosylase (MutY/MicA) protects cells against oxidative stress-induced mutagenesis by removing adenine which is mispaired with 7,8dihydro-8-oxoguanine (80xoG) in the base excision repair (BER) pathway. However, MutY does not discriminate between template and newly synthesized DNA strands. Therefore the ability to remove $A$ from $80 \times 0 G \cdot A$ mispair, which is generated via misincorporation of an 8oxodGTP precursor during DNA replication and in which $A$ is the template base, can induce $A \cdot T \rightarrow C \cdot G$ transversions. Furthermore, it has been demonstrated that human MUTYH, homologous to the bacterial MutY, might be involved in the aberrant processing of ultraviolet (UV) induced DNA damage. Methods. Here, we investigated the role of MutY in UV-induced mutagenesis in E. coli. MutY was probed on DNA duplexes containing cyclobutane pyrimidine dimers (CPD) and pyrimidine (6-4) pyrimidone photoproduct (6-4PP). UV irradiation of $E$. coli induces SOS response characterized by increased production of DNA repair enzymes and mutagenesis. To study the role of MutY in vivo, the mutation frequencies to rifampicin resistance after UV irradiation of wild type and mutant 
E. coli strains were measured. Results. We demonstrated that MutY does not excise Adenine when it is paired with CPD and 6-4PP adducts in duplex DNA. At the same time, MutY excises Adenine in $A \cdot G$ and $A \bullet 80 x 0 G$ mispairs. Interestingly, $E$. coli mutY strains, which have elevated spontaneous mutation rate, exhibited low mutational induction after UV exposure as compared to MutY-proficient strains. However, sequence analysis of rifampicin resistant mutants revealed that the frequencies of $\mathrm{C} \rightarrow \mathrm{T}$ transitions dramatically increased after UV irradiation in both MutY-proficient and -deficient E. coli strains.

Discussion. These findings indicate that the bacterial MutY is not involved in the aberrant DNA repair of UV-induced DNA damage. [p] 
*Corresponding author: murat.saparbaev@gustaveroussy.fr

\section{Aberrant repair initiated by the adenine-DNA glycosylase does not play a role in UV- induced mutagenesis in Escherichia coli}

Caroline ZUTTERLING ${ }^{1}$, Aibek MURSALIMOV ${ }^{2}$, Ibtissam TALHAOUI ${ }^{3}$, Zhanat $\mathrm{KOSHENOV}^{2}$, Zhiger AKISHEV ${ }^{4}$, Amangeldy K. BISSENBAEV 4 , Gerard MAZON ${ }^{3}$, Nicolas E. GEACINTOV ${ }^{5}$, Didier GASPARUTTO ${ }^{6}$, Regina GROISMAN ${ }^{1}$, Dmitry O. ZHARKOV ${ }^{7,8}$, Bakhyt T. MATKARIMOV ${ }^{2}$, and Murat SAPARBAEV ${ }^{1, *}$

${ }^{1}$ Groupe «Réparation de l'ADN», Equipe Labellisée par la Ligue Nationale Contre le Cancer, CNRS UMR8200, Université Paris-Sud, Gustave Roussy Cancer Campus, Villejuif, France;

2 National Laboratory Astana, Nazarbayev University, Astana, Kazakhstan;

3 CNRS UMR 8200 - Laboratoire «Stabilité Génétique et Oncogenèse», Université Paris Sud (Paris XI), Gustave Roussy Cancer Campus, Villejuif, France;

${ }^{4}$ Department of Molecular Biology and Genetics, Faculty of Biology, al-Farabi Kazakh National University, Almaty, Kazakhstan;

${ }^{5}$ Chemistry Department, New York University, New York, NY, United States;

${ }^{6}$ Université Grenoble Alpes, CEA, CNRS, INAC, SyMMES, Grenoble, France;

${ }^{7}$ SB RAS Institute of Chemical Biology and Fundamental Medicine, Novosibirsk, Russia;

${ }^{8}$ Novosibirsk State University, Novosibirsk, Russia.

ABBREVIATION FOOTNOTES: CPD, cyclobutane pyrimidine dimer; 6-4PP, pyrimidine (6glycosylase; MUTYH, human adenine-DNA glycosylase; TDG, human mismatch-specific thymine-DNA glycosylase; ANPG, human alkyl- $N$-purine DNA glycosylase; UVDE, Saccharomyces pombe UV-damage endonuclease; T4 PDG, bacteriophage T4 endonuclease V or pyrimidine dimer glycosylase; BER, base excision repair; NER, nucleotide excision repair; Rif, rifampicin. 


\section{ABSTRACT}

36 Background. DNA repair is essential to counteract damage to DNA induced by endo- and

37 exogenous factors, to maintain genome stability. However, challenges to the faithful discrimination between damaged and non-damaged DNA strands do exist, such as mismatched pairs between two regular bases resulting from spontaneous deamination of 5-methylcytosine or DNA polymerase errors during replication. To counteract these mutagenic threats to genome stability, cells evolved the mismatch-specific DNA glycosylases that can recognize and remove regular DNA bases in the mismatched DNA duplexes. The Escherichia coli adenine-DNA glycosylase (MutY/MicA) protects cells against oxidative stress-induced mutagenesis by removing adenine which is mispaired with 7,8-dihydro-8-oxoguanine (8oxoG) in the base excision repair (BER) pathway. However, MutY does not discriminate between template and newly synthesized DNA strands. Therefore the ability to remove A from 8oxoG•A mispair, which is generated via misincorporation of an 8oxodGTP precursor during DNA replication and in which $A$ is the template base, can induce $A \cdot T \rightarrow C \cdot G$ transversions. Furthermore, it has been demonstrated that human MUTYH, homologous to the bacterial MutY, might be involved in the aberrant processing of ultraviolet (UV) induced DNA damage.

Methods. Here, we investigated the role of MutY in UV-induced mutagenesis in E. coli. MutY was probed on DNA duplexes containing cyclobutane pyrimidine dimers (CPD) and pyrimidine (6-4) pyrimidone photoproduct (6-4PP). UV irradiation of E. coli induces SOS response characterized by increased production of DNA repair enzymes and mutagenesis. To study the role of MutY in vivo, the mutation frequencies to rifampicin resistance after UV irradiation of wild type and mutant $E$. coli strains were measured.

57 Results. We demonstrated that MutY does not excise Adenine when it is paired with CPD and 64PP adducts in duplex DNA. At the same time, MutY excises Adenine in $A \cdot G$ and $A \bullet 80 x o G$ mispairs. Interestingly, E. coli mut $Y$ strains, which have elevated spontaneous mutation rate,

60 exhibited low mutational induction after UV exposure as compared to MutY-proficient strains.

61 However, sequence analysis of rifampicin resistant mutants revealed that the frequencies of

$62 \mathrm{C} \rightarrow \mathrm{T}$ transitions dramatically increased after UV irradiation in both MutY-proficient and -

63 deficient E. coli strains. 
64 Discussion. These findings indicate that the bacterial MutY is not involved in the aberrant DNA 65 repair of UV-induced DNA damage. 


\section{INTRODUCTION}

68

69

70

71

72

In all cellular organisms DNA composition is limited to only four nucleotides $\mathrm{C}, \mathrm{G}, \mathrm{A}$ and $\mathrm{T}$, except for DNA methylation, which is appeared as a protection mechanism against foreign DNA or as a gene regulatory system. Noteworthy, this strict evolutionary constraint also enables DNA repair systems to distinguish between damaged and normal bases. DNA glycosylases recognize and excise modified bases among vast majority of normal bases via the base excision repair (BER) pathway. Nevertheless, a mispair composed of two normal bases occuring due to spontaneous deamination of 5-methylcytosine to thymine and DNA polymerase errors during replication presents a challenging puzzle to repair systems.

Hydroxyl radicals $(\mathrm{OH} \bullet)$ preferentially react with $\mathrm{C}_{8}$ atom of purines to generate 7,8 dihydro-8-oxoguanine (8oxoG) in DNA and 8-oxo-2'-deoxyguanosine-5'-triphosphate (8oxodGTP) in nucleotide pool. 8oxoG is a highly mutagenic DNA adduct considered as a major oxidative DNA lesion in aerobic organisms. To counteract the genotoxic effects of oxidized guanines, organisms have evolved multiple overlapping DNA repair and error-avoiding mechanisms. The majority of oxidative DNA base lesions including 8oxoG are removed in the base excision repair (BER) pathway (Barnes \& Lindahl 2004). BER is initiated by a DNA glycosylase which cleaves the $N$-glycosydic bond between the abnormal base and the deoxyribose, generating either an abasic site or single-stranded break in DNA. In E. coli, the system referred as GO pathway, which consist of three enzymes: the bi-functional 8oxoG-DNA glycosylase/AP lyase Fpg/MutM which excises the 8oxoG opposite cytosine (Tchou et al. 1991), MutY which excises adenine misincorporated across unrepaired 8oxoG in DNA template (Michaels et al. 1992) and finally MutT which cleanses cellular dNTPs pool by hydrolyzing 8oxodGTP precursors, and thus avoiding its incorporation into DNA (Maki \& Sekiguchi 1992). The crystal structure and mutagenesis studies revealed that MutY cleaves the N-glycosydic bond through a hydrolytic mechanism requiring Asp138, followed by an inefficient $\beta$-elimination reaction which is structurally and chemically uncoupled from the initial glycosydic bond cleavage (Guan et al. 1998; Manuel et al. 2004). Nevertheless, consistent with the established mechanism of action of bi-functional DNA glycosylases/AP lyases, MutY generates a Schiff base intermediate between the nucleophilic lysine and C1' of the AP site (Sun et al. 1995). Multiple evidence demonstrates that the GO pathway prevents mutations induced by oxidation of 
98 guanines in DNA and nucleotide pool in many different species. For example, the E. coli fpg 99 mut $Y$ double mutant exhibits an extreme mutator phenotype with 10,000-fold increase in $100 \mathrm{G} \cdot \mathrm{C} \rightarrow \mathrm{T} \bullet \mathrm{A}$ transversions that can be reversed by plasmids carrying the Fpg gene (Duwat et al. 101 1995). At the same time, E. coli mutT also shows a strong mutator phenotype, characterized by 102 the specific increase in $\mathrm{A} \bullet \mathrm{T} \rightarrow \mathrm{C} \cdot \mathrm{G}$ transversions (Yanofsky et al. 1966). Intriguingly, the 103 presence of $m u t Y$ mutation lowers the frequency of $\mathrm{A} \cdot \mathrm{T} \rightarrow \mathrm{C} \cdot \mathrm{G}$ spontaneous mutations in both $E$. 104 coli wild-type (WT) and mutT strains, suggesting that MutY can act in mutagenic post-replication 105 repair pathway by excising correct $\mathrm{A}$ in the template DNA strand when it is opposite a misincorporated 8oxodGTP residue (Fowler et al. 2003).

MYH (MUTYH) is a human homologue of the E. coli MutY protein, which displays very similar DNA substrate specificities to the bacterial counterpart. Mutations in MUTYH gene are associated with certain types of familial colorectal tumors without a germ-line mutation in the $A P C$ gene and they also confer a spontaneous mutator phenotype in human and mice cell lines (Al-Tassan et al. 2002). Previously, Vrouwe and colleagues have shown that exposure of the non-cycling NER-deficient XP-C and XP-A human fibroblasts to UV radiation resulted in the 113 generation and accumulation of single-strand DNA breaks 24 hours after treatment, which in turn 114 activated ATR-dependent DNA damage response (Vrouwe et al. 2011). Intriguingly, the 115 formation of single-strand DNA breaks at damage sites and DNA repair synthesis initiated by 116 these breaks did not lead to removal of UV adducts in XP fibroblasts. However, recently 117 Mazouzi and colleagues revealed that the presence of MUTYH protein in NER-deficient cells 118 results in an increased sensitivity to UV light (Mazouzi et al. 2017). The authors proposed that 119 MUTYH may inhibit the alternative NER-independent repair of UV-induced DNA lesions in XP 120 cells. Nevertheless, it might be also possible that human adenine-DNA glycosylase targets A 121 opposite UV adducts and cause aberrant futile repair of the non-damaged DNA strand. Thus, one 122 could imagine that the severe phenotype of XP patients might be due to a DNA glycosylase123 initiated aberrant repair of UV-induced DNA lesions in human cells that would lead to an 124 extremely mutagenic scenario.

125 UV radiation generates two most common DNA lesions: the cyclobutane pyrimidine 126 dimer (CPD) and the pyrimidine (6-4) pyrimidone photoproduct [(6-4)photoproduct; 6-4PP]. 127 Both photoproducts are cytotoxic (block DNA replication and transcription) and mutagenic, 128 while CPDs are several times more frequent than 6-4PPs (Douki et al. 2000). A hallmark of UV 
129 mutagenesis is the high frequency of $\mathrm{C} \rightarrow \mathrm{T}$ transitions at dipyrimidine sites in DNA, possibly 130 due to the extremely high deamination rate of cytosine residues within CPD sites in DNA (Peng 131 \& Shaw 1996). UV radiation greatly induces mutagenesis in E. coli, however mutation in the $132 \operatorname{lex} A, \operatorname{rec} A$ and $u m u D(C)$ abolish UV mutagenesis implying the existence of error-prone DNA 133 repair mechanisms. Following the pioneering studies of Witkin and Radman's hypothesis on SOS 134 repair, work by the numerous laboratories have established and characterized to a great detail the 135 E. coli SOS response system. According to the widely accepted model, following DNA damage, 136 RecA becomes activated in the presence of single-stranded DNA regions and mediates LexA 137 proteolytic cleavage which in turn leads to the increased expression of more than 40 genes 138 including recA, $u v r A$ and $u m u D C$. Genetic and biochemical evidence suggests that SOS 139 mutagenesis is largely the result of the action of error-prone translesion DNA polymerases, such 140 as Pol V (encoded by the umuDC operon), which have the ability to insert nucleotides opposite 141 various DNA lesions and thus enabling the lesion bypass and restart of stalled DNA replication 142 forks by replicative DNA polymerases (Patel et al. 2010).

143 In our previous studies, we have established the existence of the aberrant repair pathway, 144 initiated by the human mismatch-specific thymine-DNA glycosylase (TDG), which can target 145 the non-damaged DNA strand and excise thymine when it is paired with a damaged adenine 146 residue in DNA duplex (Talhaoui et al. 2014). In vitro reconstitution of BER with duplex DNA 147 containing hypoxanthine opposite $\mathrm{T}(\mathrm{Hx} \bullet \mathrm{T}$ pair) and $\mathrm{TDG}$ resulted in the incorporation of 148 cytosine opposite $\mathrm{Hx}$. Based on the mutagenic properties of mismatch-specific DNA 149 glycosylases we proposed that the aberrant BER pathway initiated by MutY in E. coli and TDG 150 and MUTYH in mammalian cells towards unrepaired DNA lesions may lead to the mutation 151 fixation in absence of DNA replication (Talhaoui et al. 2017). Here, we characterized in vitro the 152 DNA glycosylase activity of E. coli MutY protein towards short oligonucleotide duplexes 153 containing UV-DNA adducts. In addition, we analyzed mutation rates and spectra in E. coli 154 strains lacking MutY after exposure to short-wavelength UV radiation. The role of MutY155 catalyzed DNA glycosylase activity in the UV-induced mutagenesis is discussed. 


\section{METHODS SUMMARY}

160

\section{Bacterial strains, plasmids and enzymes}

162

163 All bacterial genetics procedures were performed as described (Miller 1972); these included

164 preparation of media and mutagenesis. The rich medium was the LB broth, supplemented when

165 required with either $100 \mu \mathrm{g} \cdot \mu \mathrm{L}^{-1}$ ampicillin, or $50 \mu \mathrm{g} \cdot \mu \mathrm{L}^{-1}$ kanamycine, or $100 \mu \mathrm{g} \cdot \mu \mathrm{L}^{-1}$

166 rifampicin. E. coli cells were transformed by DNA electroporation as described (Dower et al.

167 1988).

168 The E. coli K12 strains used in this study are listed in Table 1. Original Miller's strain

169 CC104, generously provided by Dr J.H. Miller (University of California, U.S.A.), is derivative of $170 \mathrm{P} 90 \mathrm{C}\left[\right.$ ara,$\left.\Delta(\text { lac proB })_{\mathrm{XIII}}\right]$ carrying a lacZ allele on an $\mathrm{F}^{\prime}\left(l_{a c I^{-}}, Z^{-}\right.$proB $\left.{ }^{+}\right)$plasmid and, therefore, 171 exhibiting the $\mathrm{Lac}^{-}$phenotype (Cupples \& Miller 1989). Strains AB1157 and CC104 (wild type

172 for DNA repair), BH200 carrying mutation in the $U v r A$ gene, BH980 in the MicA (also referred 173 as $M u t Y$ ) gene, BH1070 and BH1220 containing double mutation uvrA6 micA were from

174 laboratory stock. Strain AK146 carrying mutation in the UvrA gene was generously provided by

175 Dr. A. Kuzminov (University of Illinois, USA). Strains were grown overnight at $37^{\circ} \mathrm{C} 200 \mathrm{rpm}$.

176 Overnight cultures were then plated (stripped) on LB-agar plates and incubated overnight to get

177 single colonies.

178 The plasmid pJWT21-4 encoding the E. coli MutY/MicA protein was generously 179 provided by Dr. P. Radicella (CEA, Fontenay-aux-Roses, France). Site-directed mutation 180 aspartic acid $138 \rightarrow$ asparagine (D138N), within the MutY coding sequence in pJWT21-4 were 181 generated by the QuikChange site-directed mutagenesis kit according to the manufacturer's 182 instructions (Stratagene Europe, Amsterdam, Netherlands). Following oligonucleotide primers 183 were used to generate MutY-D138N mutant: forward primer, $184 \mathrm{~d}(\mathrm{CACTTTCCGATTCTCAACGGTAACGTCAAACG)} \mathrm{and} \mathrm{reverse} \mathrm{primer,}$ 185 d(CGTTTGACGTTACCGTTGAGAATCGGAAAGTG).

186 UV-damage endonuclease (UVDE) from Saccharomyces pombe and T4 endonuclease V 187 (T4-PDG) were purchased from Trevigen (Gaithersburg, MD, USA) and New England Biolabs 188 France SAS (Evry), respectively. The AP endonucleases from human (APE1) (Gelin et al. 2010) 189 and Mycobacterium tuberculosis (MtbXthA) (Abeldenov et al. 2015) and uracil-DNA 
190 glycosylase from E. coli (UNG) (Scaramozzino et al. 2003) are from laboratory stock. The $E$.

191 coli MutY protein was purified from E. coli B834(DE3) strain harbouring pET13a-MutY

192 plasmid as described (Zharkov et al. 2000).

193 Preparation of plasmid DNA substrate. $70 \mu \mathrm{L}$ of pBlueScript SK(+) plasmid DNA $(0.1$

$194 \mu \mathrm{g} \cdot \mathrm{mL}^{-1}$ ) in TE buffer was placed in $0.2 \mathrm{~mL}$ quartz cuvette and irradiated with $254 \mathrm{~nm}$ 195 germicidal UV at a dose of $1000 \mathrm{~J} \cdot \mathrm{m}^{-2}$ at $4^{\circ} \mathrm{C}$.

196

197 Oligonucleotides and repair assay

Oligonucleotides used in the present study are presented in the $5^{\prime} \rightarrow 3^{\prime}$ direction. The 24 mer oligonucleotides containing the CPD or 6-4PP adduct: d(CTTCTTCGCAAGXXGGAGCTCTCT) where $\mathbf{X X}$ is either CPD or 6-4PP, and 30 mer oligonucleotide containing the CPD adduct d(AGGTCTCTTCTTCTXXGCACTTCTTCCTCC) where XX is CPD, were synthesized as described previously (Smith \& Taylor 1993). All the oligodeoxyribonucleotides containing regular DNA bases residues including their complementary oligonucleotides and also oligonucleotides containing base modifications such as Uracil (U) and 7,8-dihydro-8-oxoguanine (8oxoG) were purchased from Eurogentec (Seraing, Belgium) including the following: complementary 24 mer d(AGAGAGCTCCNNCTTGCGAAGAAG) and 30 mer d(GGAGGAAGAAGTGCNNAGAAGAAGAGACCT) where NN is either AA, AG, GA and GG dinucleotide opposite UV lesion; an d(AGGTCTCTTCTTCTYYGCACTTCTTCCTCC) and modified $\quad 30$ mer d(CTTCTTCGCAAGYYGGAGCTCTCT) or d(AGAGAGCTCCYYCTTGCGAAGAAG) and where $\mathbf{Y}$ is either T, U, G or 8oxoG.

213 The oligonucleotides were 5'-end labelled with $\left[\gamma^{32} \mathrm{P}\right]$-ATP (PerkinElmer, France) and 214 then annealed with the complementary strands as described (Gelin et al. 2010). The standard 215 reaction mixture $(20 \mu \mathrm{L})$ for DNA repair assays contained $5 \mathrm{nM}$ of $\left[{ }^{32} \mathrm{P}\right]$-labelled duplex 216 oligonucleotide or $1 \mu \mathrm{g}$ of plasmid DNA, $20 \mathrm{mM}$ Tris- $\mathrm{HCl}(\mathrm{pH} 8.0), 100 \mathrm{mM} \mathrm{NaCl}, 1 \mathrm{mM}$ 217 EDTA, $1 \mathrm{mM}$ DTT, $100 \mu \mathrm{g} \cdot \mathrm{mL}^{-1} \mathrm{BSA}$ and $100 \mathrm{nM}$ MutY for $30 \mathrm{~min}$ at $37^{\circ} \mathrm{C}$, unless otherwise 218 stated. The AP sites left after excision of damaged bases in synthetic oligonucleotide substrates 219 were cleaved by incubation of the reaction mixture with light piperidine $(10 \%(\mathrm{v} / \mathrm{v})$ piperidine at $22037^{\circ} \mathrm{C}$ for $30 \mathrm{~min}$ and then neutralized by $0.1 \mathrm{M} \mathrm{HCl}$. Otherwise the plasmid DNA was incubated 
221 with $100 \mathrm{nM}$ APE1 in DNA glycosylase buffer for $30 \mathrm{~min}$ at $37^{\circ} \mathrm{C}$. The samples were desalted 222 using Sephadex G25 column (Amersham Biosciences) equilibrated in 7.5 M urea and the 223 cleavage products were separated by electrophoresis in denaturing $20 \%(\mathrm{w} / \mathrm{v})$ polyacrylamide 224 gels (7 M Urea, $\left.0.5 \mathrm{x} \mathrm{TBE}, 42^{\circ} \mathrm{C}\right)$. A Fuji Phosphor Screen was exposed to the gels and then 225 scanned with laser scanner Typhoon FLA 9500 (GE Healthcare Life Sciences) and resulting 226 digital images were analyzed using Image Gauge V3.12 software. Reaction with pBlueScript $227 \mathrm{SK}(+)$ plasmid was stopped by adding $5 \mu \mathrm{L}$ of $0.25 \%$ bromophenol blue, $50 \%$ glycerol and 10 mM EDTA and the products were analyzed by $0.8 \%$ agarose gel electrophoresis $(0.5 \mathrm{X}$ TBE).

229

230

\section{UV mutagenesis.}

231 Strains were grown overnight at $37^{\circ} \mathrm{C} 200 \mathrm{rpm}$ and then streaked on LB-agar plates and 232 incubated overnight (for 16 hours) to obtain single colonies. Single colonies for each strain were 233 grown in $10 \mathrm{~mL}$ of LB overnight at $37^{\circ} \mathrm{C}$ and $200 \mathrm{rpm}$ then culture was centrifuged and washed 234 with Phosphate-buffered saline (PBS). Cells were collected by centrifugation and pellets were 235 resuspended in the same volume of PBS and were exposed to standard germicidal UV lamp 236 emitting at $254 \mathrm{~nm}$. For this, $2 \mathrm{~mL}$ of cell suspension were irradiated in tissue culture dish with a 237 different dose of UV irradiation at $254 \mathrm{~nm}$. In general, to obtain mutation induction UV light was 238 used at a dose that produced less than 10\% survival. All procedures were performed in the dark 239 to prevent photo-reversal of UV lesions and aliquots were taken to plate on LB plates to measure 240 the survival. After irradiation, $1 \mathrm{~mL}$ of culture was diluted in $2 \mathrm{~mL}$ of fresh $\mathrm{LB}$ and incubated 241 overnight at $37^{\circ} \mathrm{C} 200 \mathrm{rpm}$. In the following day $0.1 \mathrm{~mL}$ of diluted and non-diluted overnight

242 culture were plated on LB-agar plates containing or not $100 \mu \mathrm{g} \cdot \mathrm{mL}^{-1}$ rifampicin which were 243 incubated overnight at $37^{\circ} \mathrm{C}$. After incubation survived colonies were counted and data were 244 analyzed.

246 Sequencing of mutations in the $E$. coli $r p o B$ gene from Rif ${ }^{\mathrm{R}}$ clones

247 The E. coli chromosomal DNA from rifampicin resistant clones was isolated as described (Dale 248 \& Greenaway 1984). The DNA sequencing of the $r p o B$ gene was performed as described 249 (Garibyan et al. 2003). Briefly, the DNA fragment containing the main cluster II of the $r p o B$ was 250 obtained by PCR amplification using genomic DNA with the following oligonucleotide primers: 251 d(CGTCGTATCCGTTCCGTTGG) and d(TTCACCCGGATAACATCTCGTC). The PCR DNA 
252 fragment was purified using the QIAquick PCR Purification Kit Qiagen kit. The purified PCR 253 products were then sequenced with following primer d(CGTGTAGAGCGTGCGGTGAAA) 254 using GATC service (Eurofins Genomics Company, Ebersberg, Germany). Absolute majority of 255 the mutations (>95\%) resulting in Rif $^{\mathrm{R}}$ clones in the present study were localized in cluster II. 256 


\section{RESULTS}

258

259

260

261

262

263

264

265

266

267

268

269

270

271

272

273

274

275

276

277

278

279

280

281

282

283

284

285

286

287

Construction and characterization of oligonucleotide duplexes containing UV-induced DNA adducts.

To examine DNA substrate specificity of mismatch-specific DNA glycosylases we have constructed short 24 and 30 mer duplex DNA oligonucleotides containing single CPD or 6-4PP adducts at positions $13-14$ in 24 mer and positions $15-16$ in 30 mer. For this, 5'-[ $\left.{ }^{32} \mathrm{P}\right]$-labelled modified oligonucleotides were hybridized to regular complementary strands containing two Adenine residues opposite the thymine dimers: CPD and 6-4PP. The resulting duplexes containing CPD and 6-4PP adducts were referred as $\mathrm{AA} \cdot \mathrm{T}=\mathrm{T}$ and $\mathrm{AA} \cdot \mathrm{T}-\mathrm{T}$ duplexes, where $\mathrm{T}=\mathrm{T}$ denotes CPD and T-T denotes 6-4PP, respectively. The presence of UV-DNA adducts in the duplex DNA oligonucleotides was confirmed by their incubation in the presence of T4 endonuclease V (T4-PDG), which is bi-functional DNA glycosylase/AP lyase that specifically cleaves DNA duplexes containing CPD, but not that of 6-4PP adducts, and Schizosaccharomyces pombe UV-damage endonuclease (UVDE), which recognizes both CPD and 6-4PP in duplex DNA and cleaves phosphodiester bond $5^{\prime}$ to the lesion by hydrolytic mechanism. To determine the length of cleavage products we generated size markers by incubation of the 5 '-[ $\left.{ }^{32} \mathrm{P}\right]$-labelled 24 mer regular duplex DNA oligonucleotide with the MtbXthA protein, an AP endonuclease from $M$. tuberculosis, which contains robust $3^{\prime} \rightarrow 5^{\prime}$ exonuclease activity (Fig. 1, lanes 4-6). As expected, incubation of 24 and 30 mer $\mathrm{AA} \bullet \mathrm{T}=\mathrm{T}$ and $\mathrm{AA} \bullet \mathrm{T}-\mathrm{T}$ duplexes with $\mathrm{T} 4-\mathrm{PDG}$ and UVDE resulted in the generation of 12 mer and 14 mer cleavage products, respectively (lanes 2, 3, 9 and 11-12), indicating the presence of UV adducts at positions 12 and 14 in 24 and 30 mer DNA duplexes, respectively. It should be noted that due to difference in the mechanism of actions between DNA glycosylase and endonuclease, the 12 and 14 mer cleavage products generated by T4-PDG migrated slower than the corresponding products generated by UVDE (lanes 2 vs 3 and 11 vs 12). T4-PDG excises damaged base and then cleaves the remaining AP site via $\beta$ elimination to generate the slowly migrating cleavage fragments containing the 3 '-phospho- $\alpha, \beta$ unsaturated aldehyde (PUA) group (Dodson et al. 1994). At the same time, UVDE generates faster migrating cleavage fragments with $3^{\prime}-\mathrm{OH}$ ends, which is expected from the hydrolytic mechanism of action of AP endonucleases (Hegde et al. 2008). 
E. coli MutY did not excise adenine opposite UV-induced adducts in oligonucleotide DNA duplexes

To examine whether aberrant BER could be involved in the processing of UV-induced DNA damage, the 24 mer $\mathrm{AA} \bullet \mathrm{T}=\mathrm{T}$ and $\mathrm{AA} \bullet \mathrm{T}-\mathrm{T}$ duplexes, in which non-damaged DNA strand containing A opposite the lesion is radioactively labelled with $5^{\prime}-\left[{ }^{32} \mathrm{P}\right]$, were incubated in the presence of $E$. coli MutY. After reactions the resulting AP sites were cleaved by light piperidine treatment and the products were separated on the denaturing PAGE. To determine the position of cleavage site in the non-damaged strand, we generated DNA size markers using 5 '-[ $\left.{ }^{32} \mathrm{P}\right]$-labelled 24 mer duplexes containing either single $A \cdot G$ mispair at position 12 , referred as $A A \cdot G T$, or single $\mathrm{A} \bullet 80 x o \mathrm{G}$ mispair at position 11 , referred as $\mathrm{AA} \bullet \mathrm{ToG}$ (where oG denotes 8oxoG). In addition, we constructed 24 mer single-stranded oligonucleotides with single Uracil (U) residue at positions 11 or 12 , referred as $24 \mathrm{UA}$ and 24AU, respectively. As expected, incubation of 24 mer AA•ToG duplex with MutY and 24UA with E. coli Uracil-DNA glycosylase (Ung) generated 10 mer cleavage fragment (Fig. 2, lanes 6, 8 and 11), whereas incubation of 24 mer AA $\cdot G T$ duplex and 24AU with the same enzymes generated 11 mer cleavage fragment (Fig. 2, lanes 2 and 12, and Fig. 3, lane 8). These results indicate that MutY excises mismatched A residues opposite 8oxoG and G. Importantly, no cleavage products were observed after incubation of $\mathrm{AA} \cdot \mathrm{T}=\mathrm{T}$ and $\mathrm{AA} \cdot \mathrm{T}-\mathrm{T}$ duplexes, indicating that Mut $\mathrm{Y}$ failed to recognize $\mathrm{A}$ residues opposite CPD and 6-4PP in 24 mer duplexes (Fig. 2 lanes 4 and 10, and Fig. 3, lane 10).

Next, we examined whether MutY could excise Adenines opposite CPD in an oligonucleotide duplex with different sequence context. For this, the 30 mer AA $\bullet T=T$ duplex, in which the complementary non-damaged DNA strand containing A opposite the lesion is radioactively labelled with 5 '-[ $\left.{ }^{32} \mathrm{P}\right]$, was incubated in the presence of E. coli MutY. We generated

313 DNA size markers using 5'-[32 P]-labelled 30 mer duplexes containing either single A•G mispair 314 at positions 15 and 16, referred as AA $\cdot \mathrm{GT}$ and $\mathrm{AA} \cdot \mathrm{TG}$, respectively. As expected, incubation of 31530 mer AA•GT and AA•TG duplexes with MutY generated 15 and 14 mer cleavage fragments, 316 respectively (Fig. 3, lanes 2 and 4). Again, no cleavage products were observed after incubation 317 of $\mathrm{AA} \cdot \mathrm{T}=\mathrm{T}$ duplex with MutY, indicating that MutY does not recognize A residues opposite 318 CPD placed in two different sequence contexts (lane 6). In addition, we measured MutY activity 
319 on the mismatched 24 and 30 mer oligonucleotide duplexes containing CPD opposite 4 possible

320 bipurine dinucleotides: GG, AG, GA and AA. The results showed no cleavage products after 321 incubation of $\mathrm{GG} \cdot \mathrm{T}=\mathrm{T}, \mathrm{AG} \cdot \mathrm{T}=\mathrm{T}, \mathrm{GA} \cdot \mathrm{T}=\mathrm{T}$ and $\mathrm{AA} \cdot \mathrm{T}=\mathrm{T}$ duplexes with MutY (Fig. S1),

322 indicating that the adenine-DNA glycosylase does not recognize A or G residues opposite CPD

323 in the mismatched DNA duplexes.

324 Still, one cannot exclude that MutY may act on Adenines opposite other bipyrimidine 325 photoproducts such as $\mathrm{C}=\mathrm{T}, \mathrm{T}=\mathrm{C}$ and $\mathrm{C}=\mathrm{C}$. To examine this, we incubated heavily UV-irradiated 326 covalently closed circular plasmid DNA (ccc) with MutY, APE1 and T4 PDG. Upon cleavage at 327 the site of damage by a DNA repair enzyme, the ccc form is converted either to an open circular 328 form (oc) or to a linear double-stranded fragment (lds) and these three forms can be separated 329 and quantified by electrophoresis in agarose gel (Ishchenko et al. 2003). The results showed that 330 while T4 PDG cleaves $97 \%$ of the UV-irradiated plasmid, MutY (both in the absence and in the 331 presence of APE1) cleaves only tiny fraction of the plasmid (Fig. S2). These results further 332 substantiate the fact that MutY has very little or no activity towards UV adducts and Adenines on 333 non-damaged strand in UV-irradiated DNA.

\section{UV-induced Rif ${ }^{S} \rightarrow$ Rif $^{R}$ mutations in MutY and NER-deficient E. coli mutants.}

Genetic and biochemical studies of $E$. coli have established that both the RecA-dependent recombination and NER pathway participate in the removal of UV-induced DNA damage. Subsequently, it was demonstrated that UV-DNA adducts can be bypassed by UmuD' ${ }_{2} \mathrm{C}-\mathrm{RecA}-$ ATP complex in vitro with high efficiency (Jiang et al. 2009). Importantly, in the absence of functional NER system, the frequency of UV-induced mutagenesis for a given dose increases further because of the persistence of unrepaired UV adduct in DNA which in turn stimulate mutations via UmuDC-dependent pathway. To examine a potential role of the MutY-catalyzed DNA glycosylase activity in UV-induced mutagenesis, we assessed the sensitivity and mutagenesis of the E. coli MutY/MicA (micA) and NER (uvrA6) deficient strains exposed to 254 nm UV light. Previously, we hypothesized that the aberrant BER pathway induces mutation in replication-independent manner (Talhaoui et al. 2014). Furthermore, it has been demonstrated that UV-induced DNA lesions can undergo mutation fixation by the NER-induced mutagenesis (NERiM) in DNA replication-independent manner (Janel-Bintz et al. 2017). Therefore, to favour 
350 the detection of mutations occurring in a DNA replication-independent manner, we measured

$351 \mathrm{UV}$-induced mutagenesis in stationary phase cultures of the E. coli wild-type CC104 and

352 AB1157 (WT), MutY-deficient BH980 (micA::Kn $\left.{ }^{R}\right)$, NER-deficient AK146 (uvrA6) and double

353 NER/MutY-deficient BH1220 (uvrA6 micA) strains. Data from a typical experiment are shown

354 in Table 2, exposure of the CC104 WT strain to high doses of UV $\left(180 \mathrm{~J} \cdot \mathrm{m}^{-2}\right)$ resulted in 64-fold

355 increase in the appearance of rifampicin-resistant $\left(\mathrm{Rif}^{\mathrm{R}}\right)$ colonies as compared to that of non-

356 irradiated strain. At the same time, BH980 strain, isogenic to CC104, but micA exhibited only

357 11-fold increase. Similarly, exposure of AK146 strain to low dose of UV $\left(10 \mathrm{~J} \cdot \mathrm{m}^{-2}\right)$ resulted in

358 81-fold increase of $\operatorname{Rif}^{\mathrm{S}} \rightarrow \mathrm{Rif}^{\mathrm{R}}$ mutations frequencies as compared to the non-irradiated control

359 (Table 2). Intriguingly, exposure of NER/MutY-deficient BH1220 strain to low dose of UV (10

$360 \mathrm{~J} \cdot \mathrm{m}^{-2}$ ) showed only weak 3.9-fold increase in frequency of UV-induced Rif ${ }^{\mathrm{R}}$ colonies as

361 compared to the non-irradiated control. It should be stressed, that MutY-deficient strains ( $m i c A)$

362 exhibited 11 to 80-fold increase in spontaneous mutation rates as compared to MutY-proficient

363 strains (Table 2). Combining data from several independent experiments in Fig. 4 demonstrated

364 that WT and NER-deficient E. coli strains exhibited 45-220-fold increase in the UV-induced

365 mutation frequencies, as compared to moderate 2.3 and 13 fold increase for MutY/NER and

366 MutY-deficient strains, respectively. Taken together, these results suggest that in absence of the

367 MutY protein, bacterial cells exhibited low to moderate induction of the UV-induced Rif ${ }^{\mathrm{S}} \rightarrow \mathrm{Rif}^{\mathrm{R}}$

368 mutations frequencies.

369

370

371 mic $A$ strains.

Molecular spectra of spontaneous and $U$ V-induced Rif $^{S} \rightarrow$ Rif $f^{R}$ mutations in E. coli WT and

372 To further examine whether MutY participates in the aberrant processing of the

373 unrepaired UV lesions in vivo, we measured UV-induced mutagenesis in the NER/MutY-

374 deficient E. coli BH1220 and BH1070 (uvrA6 micA) strains harbouring vector pJWT21-4 coding

375 either for MutY-WT or for catalytically inactive mutant MutY-D138N. It should be noted that

376 the BH1220 and BH1070 strains expressing MutY-WT exhibited very low rate of spontaneous

377 mutations as compared to the same strains expressing mutant MutY-D138N. As expected,

378 exposure of the BH1220 and BH1070 strains with MutY-WT to UV $\left(10 \mathrm{~J} \cdot \mathrm{m}^{-2}\right)$ resulted in more

379 than 100-fold increase in Rif $^{\mathrm{S}} \rightarrow \mathrm{Rif}^{\mathrm{R}}$ mutation frequencies (Fig. 5). In contrast, for the same dose

380 of UV, these same strains but containing MutY-D138N mutant exhibited only 3-7 fold increase 
381 in the UV-induced mutations (Fig. 5). It is well established that the major type of mutations

382 induced by UV light are $\mathrm{C} \rightarrow \mathrm{T}$ transitions. Since the majority of spontaneous mutations in MutY-

383 deficient strains are due to oxidative damage to guanines in DNA, we suggested that the majority

384 of UV-induced mutations in these strains would be due to cytosine-containing pyrimidine dimers

385 in DNA and not due to guanine oxidation.

386 To examine changes in the mutation spectra in $W T$ and DNA repair-deficient E. coli 387 strains after UV exposure, we performed DNA sequencing of RpoB gene from Rif ${ }^{\mathrm{R}}$ clones 388 obtained before and after UV exposure of the cells. As expected, analysis of the spontaneous and $389 \mathrm{UV}$-induced mutation spectra in the E. coli WT, uvrA6 and uvrA6 micA strains revealed that all 390 strains exhibit dramatic increase in the frequency of $\mathrm{C} \cdot \mathrm{G} \rightarrow \mathrm{T} \cdot \mathrm{A}$ transition: from $12.6 \%$ to $81 \%$ in $391 W T$ and from $2.6-6.5 \%$ to $64-76 \%$ in $u v r A 6$ mic $A$ strains (Table 3). It should be noted that 392 BH1070 and BH1220 strains, as compared to the MutY-proficient strains, exhibited moderate 393 increase in the overall mutation frequencies after UV exposure, possibly because of the masking 394 effect of high spontaneous mutation rate in non-exposed cells which is primarily due to $395 \mathrm{G} \bullet \mathrm{C} \rightarrow \mathrm{T} \bullet \mathrm{A}$ transversions (which make $>80 \%$ of all mutations). Remarkably, UV irradiation 396 dramatically changes the mutation spectra in these two uvrA6 micA strains with majority of 397 mutations being $\mathrm{C} \cdot \mathrm{G} \rightarrow \mathrm{T} \bullet \mathrm{A}$ transitions (which make $64-76 \%$ of all $\mathrm{UV}$-induced mutations after 398 UV exposure (Table 3). Using these mutation spectra, we calculated the relative increase in the 399 frequency of $\mathrm{C} \bullet \mathrm{G} \rightarrow \mathrm{T} \bullet \mathrm{A}$ transitions after UV irradiation. The results revealed that NER/MutY400 deficient BH1220 and BH1070 strains exhibited dramatic 86 and 239 fold increase, in the 401 frequency of $\mathrm{C} \cdot \mathrm{G} \rightarrow \mathrm{T} \bullet \mathrm{A}$ transitions after $\mathrm{UV}$ exposure, although the overall increase in $402 \mathrm{Rif}^{\mathrm{S}} \rightarrow \mathrm{Rif}^{\mathrm{R}}$ mutation frequencies were only 3.9-4.5 fold (Table 3).

403 Of note, the mutational signatures in the control non-irradiated strains varied depending 404 on the genetic background. For example, of the most frequent base substitution in non-irradiated $405 \mathrm{AB} 1157(W T)$ was $\mathrm{T} \bullet \mathrm{A} \rightarrow \mathrm{C} \bullet \mathrm{G}$ transition followed by $\mathrm{A} \bullet \mathrm{T} \rightarrow \mathrm{C} \bullet \mathrm{G}$ transversion (Table 3 ). At the 406 same time, $\mathrm{C} \cdot \mathrm{G} \rightarrow \mathrm{A} \bullet \mathrm{T}$ transitions were prevalent in the non-irradiated $\mathrm{BH} 200(u v r A: \because \operatorname{Tn} 10)$ and 407 AK146 (uvrA6) strains. 408 409 Structural features counteracting the aberrant DNA substrate specificity of MutY.

410 The reported opposite-base specificity of MutY includes naturally occurring bases 8oxoG, 411 G, C (Radicella et al. 1988; Tsai-Wu et al. 1992), 8-oxoadenine (Bulychev et al. 1996) as well as 
412 artificial base analogs 8-oxohypoxanthine, 8-oxonebularine, 8-methoxyguanine, 8-thioguanine, 413 7-methyl-8-oxoguanine, and 8-bromoguanine (Bulychev et al. 1996; Manlove et al. 2017). The 414 structure of MutY from Geobacillus stearothermophilus (Bst-MutY) bound to DNA containing 415 an A:8oxoG mispair reveals intrahelical 8oxoG forming specific hydrogen bonds with a 416 conserved Ser residue, $\mathrm{O}^{8}[80 x 0 \mathrm{G}] \ldots \mathrm{N}[\mathrm{S} 308]$ and N7[8oxoG]...O $\gamma[\mathrm{S} 308]$ (Fromme et al. 2004; 417 Lee \& Verdine 2009). However, this arrangement of hydrogen bonds is not possible with $\mathrm{G}$ and 418 many other bases opposite the excised adenine. It has been suggested that for DNA glycosylases 419 excising canonical bases from non-canonical base pairs, such as MutY, the decisive factor is 420 selective destabilization of a non-canonical base pair and stabilization of the everted natural base 421 in the enzyme-substrate complex (Talhaoui et al. 2017).

422 In order to rationalize the lack of activity of MutY on A opposite CPD, we have analysed 423 the structures of all available MutY-DNA complexes (Fromme et al. 2004; Lee \& Verdine 2009; 424 Wang et al. 2017; Wang et al. 2015) and all DNA molecules containing a CPD (Biertumpfel et al. 425 2010; Fischer et al. 2011; Horikoshi et al. 2016; Li et al. 2004; McAteer et al. 1998; Park et al. 426 2002; Silverstein et al. 2010; Vasquez-Del Carpio et al. 2011; Vassylyev et al. 1995). By 427 covalently linking two adjacent residues, a CPD places strong constraints on the geometry of the 428 damaged nucleotides, keeping them closer than in regular B-DNA $\left(\mathrm{C} 1{ }^{\prime}-\mathrm{C} 1\right.$ ' distance $4293.85 \pm 0.29 \AA$ in a CPD vs $5.17 \pm 0.45 \AA$ in B-DNA). On the other hand, intrusion of an aromatic 430 residue (Tyr88 in Bst-MutY) $5^{\prime}$ of $80 x o G$ stretches DNA in this region $\left(\mathrm{C}^{\prime}-\mathrm{C}^{\prime}\right.$ distance

$4317.22 \pm 0.61 \AA$ ) and slightly compresses it $3^{\prime}$ of 8 oxoG $(4.50 \pm 0.23 \AA)$. Thus, a covalently bound $432 \mathrm{CPD}$ is incompatible with the geometry requirements to the non-cleaved strand in a MutY-DNA 433 complex targeting either 5'- or 3'-adenine in the AA dinucleotide opposite a CPD (Fig. 6). 


\section{DISCUSSION}

437 Recently, we showed that human TDG can target non-damaged DNA strand to remove 438 mismatched $\mathrm{T}$ opposite deaminated/oxidized adenine residues in duplex DNA in TpG/CpA* 439 context (where $A^{*}$ is a damaged adenine residue). This aberrant excision of a normal base 440 initiates repair synthesis that uses damaged DNA template leading to $\mathrm{T} \rightarrow \mathrm{C}$ mutation fixation in 441 the absence of DNA replication. This finding points to a possible role of other mismatch-specific 442 DNA glycosylases which do not discriminate damaged versus non-damaged DNA strand when 443 excising regular DNA bases such as bacterial MutY and human MUTYH proteins. Indeed, it was 444 shown that E. coli MutY participates in mutagenic post-replicative excision of regular A opposite 445 a misincorporated $80 x 0 \mathrm{G}$ residue which results in the increased $\mathrm{A} \bullet \mathrm{T} \rightarrow \mathrm{C} \bullet \mathrm{G}$ transversion rates in 446 both E. coli wild-type (WT) and mutT strains (Fowler et al. 2003). It has been also demonstrated 447 that MUTYH is involved in aberrant processing of UV lesions and interferes with NER 448 machinery (Mazouzi et al. 2017). Based on these observations we speculated that 449 MutY/MUTYH similar to TDG/MBD4 may initiate aberrant excision of Adenines opposite 450 damaged Thymine residues, for example CPD and 6-4PP adducts, which in turn may lead to 451 futile repair and activation of the DNA damage response in the UV-exposed cells.

452 In the present study, we report that the E. coli MutY protein cannot excise A residues 453 opposite UV-induced CPD and 6-4PP adducts in the duplex oligonucleotide under experimental 454 conditions used. Importantly, we observed efficient MutY-catalyzed excision of mismatched A 455 residues when opposite $\mathrm{G}$ and 8oxoG residues in duplex DNA with the same sequence contexts 456 used for UV lesions. These biochemical results suggest that MutY and perhaps its human 457 homologue MUTYH do not participate in UV-induced mutagenesis in bacterial and human cells, 458 respectively. The inability of MutY to excise A from opposite a CPD seems to be due, at least in 459 part, to a severe conformational restrictions inflicted by the covalent linkage between two 460 pyrimidines: the distance between two thymines in a dimer is less than is required to fit into 461 MutY active center and cannot be widened (Fig. 6). Thus, the pre-catalytic MutY-DNA complex 462 with a CPD would be destabilized, and the efficiency of the reaction significantly compromised.

463 To clear out the possible role of MutY in the aberrant mutagenic repair, we examined 464 whether UV-induced mutagenesis in E. coli depends on the presence of this mismatch-specific 465 DNA glycosylase. We observed that after UV exposure the MutY-deficient E. coli strains 
466 exhibited lower induction of $\mathrm{Rif}^{\mathrm{S}} \rightarrow \mathrm{Rif}^{\mathrm{R}}$ mutations as compared to MutY-proficient strains 467 (Table 2 and Fig. 4). It should be stressed that under normal conditions E. coli micA strains 468 exhibit a 100-fold increase in the spontaneous mutation rates as compared to MutY/MicA469 proficient strains (Nghiem et al. 1988). Actually, this spontaneous mutator phenotype of E. coli 470 micA strains might conceal the mutagenic effect of UV light, which, under the experimental 471 conditions used, induces mutations at similar rates. Thus, we have analyzed mutation spectra in 472 E. coli strains before and after UV exposure to see whether the types of mutations changes in 473 MutY-deficient cells. The DNA sequence analysis of Rif ${ }^{\mathrm{R}}$ clones showed that the NER/MutY474 deficient $\mathrm{BH} 1220$ and $\mathrm{BH} 1070$ strains exhibited dramatic 86- and 239-fold increase in the 475 frequency of $\mathrm{C} \cdot \mathrm{G} \rightarrow \mathrm{T} \bullet \mathrm{A}$ transitions after $\mathrm{UV}$ exposure, although the overall increase in $476 \mathrm{Rif}^{\mathrm{S}} \rightarrow \mathrm{Rif}^{\mathrm{R}}$ mutation frequencies was only 3.9- and 4.5-fold (Table 3). These results indicate that 477 the mutation spectra in MutY/MicA-proficient and -deficient cells change in similar manner after $478 \mathrm{UV}$ exposure. It appears that MutY does not play a significant role in the induction of $\mathrm{C} \bullet \mathrm{G} \rightarrow \mathrm{T} \bullet \mathrm{A}$ 479 transitions after UV exposure in vivo. Nevertheless, recently, it has been demonstrated that the 480 repair of UV-induced DNA lesions turns out to be mutagenic in non-dividing cells under certain 481 circumstances. Indeed, Janel-Bintz and colleagues have demonstrated that in E. coli cells the 482 removal of closely spaced UV lesions in the NER pathway can induce mutations which are not 483 depend on DNA replication (Janel-Bintz et al. 2017). Interestingly, NER-induced mutagenesis 484 (NERiM) operates in stationary phase cells and requires DNA polymerases IV and II. In line 485 with these observations, it has been shown that active Pol V complex (UmuD' ${ }_{2} \mathrm{C}-\mathrm{RecA}-\mathrm{ATP}$ ) 486 formed after UV irradiation do not co-localize with replicative DNA polymerase III complexes 487 (Robinson et al. 2015).

488 Although in the present study we did not observe aberrant repair activities of MutY in $E$. 489 coli cells, evidence accumulates showing that mammalian homologues of MutY are involved in 490 the aberrant futile DNA repair. Depletion of MUTYH by acetohexamide in XP cells promotes an 491 alternative repair of UV-induced lesions and increases cells survival (Mazouzi et al. 2017). 492 Under increased oxidative stress and in the absence of OGG1, the MUTYH-mediated BER might 493 become futile and cytotoxic (Nakabeppu 2014; Sheng et al. 2012). Also, it has been 494 demonstrated that MUTYH induces persistent accumulation of SSBs in the nascent DNA strand 495 which in turn promotes MLH1/PARP1-dependent human cell death (Oka et al. 2014) and retinal 496 inflammation and degeneration in a mouse model of Retinis pigmentosa (Nakatake et al. 2016). 
497 A possible role of the MUTYH-initiated aberrant BER in DNA damage response was suggested

498 by the study of the mechanisms of neurodegeneration caused by 3-nitropropionic acid (3NP)

499 (Sheng et al. 2012). The authors showed that 3NP induced oxidative stress results in an

500 accumulation of $80 x 0 \mathrm{G}$ and SSBs in the mitonchondrial DNA of neurons. SSBs accumulation

501 and neurodegeneration were alleviated in mutant mice lacking MUTYH, whereas OGG1 and

502 MTH1, a 80xo-dGTP hydrolase, offered protection, suggesting that aberrant repair of the

503 misincorporated adenine opposite 8oxoG in DNA by MUTYH leads to SSB accumulation,

504 which in turn triggers mitochondrial impairment and retrograde signalling to the nucleus of 505 neurons.

506

\section{CONCLUSION}

508

509

In the present study we further characterized the biochemical and genetic properties of well-known bacterial MutY DNA glycosylase. The data demonstrated that bacterial MutY does not recognize A opposite damaged $\mathrm{T}$ residues such as pyrimidine dimers in duplex DNA and is not involved in UV-induced mutagenesis in E. coli. Based on these observations, we propose that

513 the role of MUTYH, a human homologue of MutY, in the increased genotoxicity of UV damage

514 in XP cells might not be due to its aberrant activity towards A residues in the non-damaged DNA

515 strand. Although we did not find clear evidence for the involvement of MutY-like DNA

516 glycosylases in the aberrant mutagenic repair, we cannot exclude that the non-dividing cells such

517 as reversibly growth-arrested dormant hematopoietic stem cells or terminally differentiated

518 neurons may be prone to the aberrant excision of regular DNA bases in damaged DNA duplexes

519 by the mono-functional mismatch-specific DNA glycosylases. Additional studies are required to

520 investigate whether MutY and MUTYH act on different DNA substrates with damaged Thymine 521 residues.

522

523

524 Acknowledgements. We are grateful to S. Boiteux and J. H. Miller for the E. coli strains. This 525 work was supported by grants to Murat Saparbaev from la Ligue National Contre le Cancer 526 "Equipe Labellisee", Electricité de France (RB 2017) and French National Center for Scientific 527 Research (PRC CNRS/RFBR n1074 REDOBER); and to Bakhyt T. Matkarimov from Science 
528 Committee of the Ministry of Education and Science of the Republic of Kazakhstan, Program 529 0212/PTF-14-OT and grant 3755/GF4; and to Dmitry O. Zharkov from the Russian Ministry of 530 Science and Education (6.5773.2017/6.7) and Russian Science Foundation (17-14-01190), and

531 to Amangeldy K. Bissenbaev from the Science Committee of the Ministry of Education and 532 Science of the Republic of Kazakhstan [grant No. AP05131598], and to Nicolas E. Geacintov 533 from US NIEHS Grant ES024050. Didier Gasparutto thanks the Arcane Labex program, funded 534 by the French National Research Agency (ARCANE project no. ANR-12-LABX-003). Ibtissam 535 Talhaoui was supported by postdoctoral fellowships from the Fondation ARC.

536

537 Author Contributions.

538 - Caroline Zutterling, Ibtissam Talhaoui, Aibek Mursalimov and Zhiger Akishev performed all 539 of the biochemical experiments.

540 - Caroline Zutterling, Ibtissam Talhaoui, Aibek Mursalimov, Zhanat Koshenov and Gerard 541 Mazon performed all of the genetic experiments.

542 - Didier Gasparutto and Nicolas E. Geacintov designed and prepared key modified DNA 543 substrates.

544 - Dmitry O. Zharkov designed and performed all molecular modelling and structural studies.

545 - Murat Saparbaev, Nicolas E. Geacintov, Didier Gasparutto, Regina Groisman, Dmitry O.

546 Zharkov, Bakhyt Matkarimov and Amangeldy K. Bissenbaev designed all experiments and 547 analyzed data.

548 - Murat Saparbaev wrote the manuscript.

549 - All authors discussed the results and contributed to the manuscript. 550

\section{Competing financial interests}

552 The authors declare no competing financial interests.

553

\section{Corresponding author}

555 Correspondence to: Murat Saparbaev 556 
558

559

560

561

562

563

564

565

566

567

568

569

570

571

572

573

574

575

576

577

578

579

580

581

582

583

584

585

586

587

588

589

590

591

592

593

594

595

596

597

598

599

600

601

602

603

604

605

606

607

608

609

610

611

612

\section{References}

Abeldenov S, Talhaoui I, Zharkov DO, Ishchenko AA, Ramanculov E, Saparbaev M, and Khassenov B. 2015. Characterization of DNA substrate specificities of apurinic/apyrimidinic endonucleases from Mycobacterium tuberculosis. DNA Repair (Amst) 33:1-16. S1568-7864(15)00129-9 [pii]

10.1016/j.dnarep.2015.05.007

Al-Tassan N, Chmiel NH, Maynard J, Fleming N, Livingston AL, Williams GT, Hodges AK, Davies DR, David SS, Sampson JR, and Cheadle JP. 2002. Inherited variants of MYH associated with somatic G:C-->T:A mutations in colorectal tumors. Nat Genet 30:227-232. 10.1038/ng828

ng828 [pii]

Barnes DE, and Lindahl T. 2004. Repair and genetic consequences of endogenous DNA base damage in mammalian cells. Annu Rev Genet 38:445-476.

Biertumpfel C, Zhao Y, Kondo Y, Ramon-Maiques S, Gregory M, Lee JY, Masutani C, Lehmann AR, Hanaoka F, and Yang W. 2010. Structure and mechanism of human DNA polymerase eta. Nature 465:1044-1048. nature09196 [pii]

10.1038/nature09196

Bulychev NV, Varaprasad CV, Dorman G, Miller JH, Eisenberg M, Grollman AP, and Johnson F. 1996. Substrate specificity of Escherichia coli MutY protein. Biochemistry 35:13147-13156.

Cupples CG, and Miller JH. 1989. A set of lacZ mutations in Escherichia coli that allow rapid detection of each of the six base substitutions. Proc Natl Acad Sci U S A 86:5345-5349.

Dale JW, and Greenaway PJ. 1984. Preparation of chromosomal DNA from E. coli. In: Walker JM, ed. Methods in Molecular Biology. Clifton, New Jersey: Humana Press, 197-200.

Dodson ML, Michaels ML, and Lloyd RS. 1994. Unified catalytic mechanism for DNA glycosylases. J Biol Chem 269:32709-32712.

Douki T, Court M, Sauvaigo S, Odin F, and Cadet J. 2000. Formation of the main UV-induced thymine dimeric lesions within isolated and cellular DNA as measured by high performance liquid chromatography-tandem mass spectrometry. J Biol Chem 275:11678-11685.

Dower WJ, Miller JF, and Ragsdale CW. 1988. High efficiency transformation of E. coli by high voltage electroporation. Nucleic Acids Res 16:6127-6145.

Duwat P, de Oliveira R, Ehrlich SD, and Boiteux S. 1995. Repair of oxidative DNA damage in gram-positive bacteria: the Lactococcus lactis Fpg protein. Microbiology 141 ( Pt 2):411-417.

Fischer ES, Scrima A, Bohm K, Matsumoto S, Lingaraju GM, Faty M, Yasuda T, Cavadini S, Wakasugi M, Hanaoka F, Iwai S, Gut H, Sugasawa K, and Thoma NH. 2011. The molecular basis of CRL4DDB2/CSA ubiquitin ligase architecture, targeting, and activation. Cell 147:1024-1039. S0092-8674(11)01285-2 [pii]

10.1016/j.cell.2011.10.035

Fowler RG, White SJ, Koyama C, Moore SC, Dunn RL, and Schaaper RM. 2003. Interactions among the Escherichia coli mutT, mutM, and mutY damage prevention pathways. DNA Repair (Amst) 2:159-173. S1568786402001933 [pii]

Fromme JC, Banerjee A, Huang SJ, and Verdine GL. 2004. Structural basis for removal of adenine mispaired with 8-oxoguanine by MutY adenine DNA glycosylase. Nature 427:652-656. 10.1038/nature02306

nature02306 [pii]

Garibyan L, Huang T, Kim M, Wolff E, Nguyen A, Nguyen T, Diep A, Hu K, Iverson A, Yang H, and Miller JH. 2003. Use of the rpoB gene to determine the specificity of base substitution mutations on the Escherichia coli chromosome. DNA Repair (Amst) 2:593-608. S1568786403000247 [pii]

Gelin A, Redrejo-Rodriguez M, Laval J, Fedorova OS, Saparbaev M, and Ishchenko AA. 2010. Genetic and biochemical characterization of human AP endonuclease 1 mutants deficient in nucleotide incision repair activity. PLoS One 5:e12241. 10.1371/journal.pone.0012241

Guan Y, Manuel RC, Arvai AS, Parikh SS, Mol CD, Miller JH, Lloyd S, and Tainer JA. 1998. MutY catalytic core, mutant and bound adenine structures define specificity for DNA repair enzyme superfamily. Nat Struct Biol 5:1058-1064.

Hegde ML, Hazra TK, and Mitra S. 2008. Early steps in the DNA base excision/single-strand interruption repair pathway in mammalian cells. Cell Res 18:27-47.

Horikoshi N, Tachiwana H, Kagawa W, Osakabe A, Matsumoto S, Iwai S, Sugasawa K, and Kurumizaka H. 2016. Crystal structure of the nucleosome containing ultraviolet light-induced cyclobutane pyrimidine dimer. Biochem Biophys Res Commun 471:117-122. S0006-291X(16)30170-X [pii] 
613 10.1016/j.bbrc.2016.01.170

614 Ishchenko AA, Sanz G, Privezentzev CV, Maksimenko AV, and Saparbaev M. 2003. Characterisation of new

615

616 substrate specificities of Escherichia coli and Saccharomyces cerevisiae AP endonucleases. Nucleic Acids Res 31:6344-6353.

617 Janel-Bintz R, Napolitano RL, Isogawa A, Fujii S, and Fuchs RP. 2017. Processing closely spaced lesions during

618

619

620

621

622

623

624

625

626

627

628

629

630

631

632

633

634

635

636

637

638

639

640

641

642

643

644

645

646

647

648

649

650

651

652

653

654

655

656

657

658

659

660

661

662

663

664

665

666 Nucleotide Excision Repair triggers mutagenesis in E. coli. PLoS Genet 13:e1006881. 10.1371/journal.pgen.1006881

PGENETICS-D-17-00386 [pii]

Jiang Q, Karata K, Woodgate R, Cox MM, and Goodman MF. 2009. The active form of DNA polymerase V is UmuD'(2)C-RecA-ATP. Nature 460:359-363. nature08178 [pii]

10.1038 /nature 08178

Lee S, and Verdine GL. 2009. Atomic substitution reveals the structural basis for substrate adenine recognition and removal by adenine DNA glycosylase. Proc Natl Acad Sci U S A 106:18497-18502. 0902908106 [pii]

10.1073/pnas.0902908106

Li Y, Dutta S, Doublie S, Bdour HM, Taylor JS, and Ellenberger T. 2004. Nucleotide insertion opposite a cis-syn thymine dimer by a replicative DNA polymerase from bacteriophage T7. Nat Struct Mol Biol 11:784-790. $10.1038 / \mathrm{nsmb} 792$

nsmb792 [pii]

Maki H, and Sekiguchi M. 1992. MutT protein specifically hydrolyses a potent mutagenic substrate for DNA synthesis. Nature 355:273-275.

Manlove AH, McKibbin PL, Doyle EL, Majumdar C, Hamm ML, and David SS. 2017. Structure-Activity Relationships Reveal Key Features of 8-Oxoguanine: A Mismatch Detection by the MutY Glycosylase. ACS Chem Biol 12:2335-2344. 10.1021/acschembio.7b00389

Manuel RC, Hitomi K, Arvai AS, House PG, Kurtz AJ, Dodson ML, McCullough AK, Tainer JA, and Lloyd RS. 2004. Reaction intermediates in the catalytic mechanism of Escherichia coli MutY DNA glycosylase. $J$ Biol Chem 279:46930-46939.

Mazouzi A, Battistini F, Moser SC, Ferreira da Silva J, Wiedner M, Owusu M, Lardeau CH, Ringler A, Weil B, Neesen J, Orozco M, Kubicek S, and Loizou JI. 2017. Repair of UV-Induced DNA Damage Independent of Nucleotide Excision Repair Is Masked by MUTYH. Mol Cell 68:797-807 e797. S1097-2765(17)30796-7 [pii]

10.1016/j.molcel.2017.10.021

McAteer K, Jing Y, Kao J, Taylor JS, and Kennedy MA. 1998. Solution-state structure of a DNA dodecamer duplex containing a Cis-syn thymine cyclobutane dimer, the major UV photoproduct of DNA. J Mol Biol 282:1013-1032. S0022-2836(98)92062-9 [pii]

10.1006/jmbi.1998.2062

Michaels ML, Tchou J, Grollman AP, and Miller JH. 1992. A repair system for 8-oxo-7,8-dihydrodeoxyguanine. Biochemistry 31:10964-10968.

Miller JH. 1972. A short course in bacterial genetics. A laboratory manual and handbook for Escherichia coli and related bacteria. NY: Cold Spring Harbor Laboratory Press, Cold Spring Harbor.

Nakabeppu Y. 2014. Cellular levels of 8-oxoguanine in either DNA or the nucleotide pool play pivotal roles in carcinogenesis and survival of cancer cells. Int J Mol Sci 15:12543-12557. ijms150712543 [pii]

10.3390/ijms 150712543

Nakatake S, Murakami Y, Ikeda Y, Morioka N, Tachibana T, Fujiwara K, Yoshida N, Notomi S, Hisatomi T, Yoshida S, Ishibashi T, Nakabeppu Y, and Sonoda KH. 2016. MUTYH promotes oxidative microglial activation and inherited retinal degeneration. JCI Insight 1:e87781. 10.1172/jci.insight.87781

87781 [pii]

Nghiem Y, Cabrera M, Cupples CG, and Miller JH. 1988. The mutY gene: a mutator locus in Escherichia coli that generates G.C----T.A transversions. Proc Natl Acad Sci U S A 85:2709-2713.

Oka S, Leon J, Tsuchimoto D, Sakumi K, and Nakabeppu Y. 2014. MUTYH, an adenine DNA glycosylase, mediates p53 tumor suppression via PARP-dependent cell death. Oncogenesis 3:e121. oncsis201435 [pii]

10.1038/oncsis.2014.35

Park H, Zhang K, Ren Y, Nadji S, Sinha N, Taylor JS, and Kang C. 2002. Crystal structure of a DNA decamer containing a cis-syn thymine dimer. Proc Natl Acad Sci USA 99:15965-15970. 10.1073/pnas.242422699

242422699 [pii] 
667

668

669

670

671

672

673

674

675

676

677

678

679

680

681

682

683

684

685

686

687

688

689

690

691

692

693

694

695

696

697

698

699

700

701

702

703

704

705

706

707

708

709

710

711

712

713

714

715

716

717

718

719

720

721

722

Patel M, Jiang Q, Woodgate R, Cox MM, and Goodman MF. 2010. A new model for SOS-induced mutagenesis: how RecA protein activates DNA polymerase V. Crit Rev Biochem Mol Biol 45:171-184. 10.3109/10409238.2010.480968

Peng W, and Shaw BR. 1996. Accelerated deamination of cytosine residues in UV-induced cyclobutane pyrimidine dimers leads to CC-->TT transitions. Biochemistry 35:10172-10181. 10.1021/bi960001x

bi960001x [pii]

Radicella JP, Clark EA, and Fox MS. 1988. Some mismatch repair activities in Escherichia coli. Proc Natl Acad Sci $U S$ A 85:9674-9678.

Robinson A, McDonald JP, Caldas VE, Patel M, Wood EA, Punter CM, Ghodke H, Cox MM, Woodgate R, Goodman MF, and van Oijen AM. 2015. Regulation of Mutagenic DNA Polymerase V Activation in Space and Time. PLoS Genet 11:e1005482. 10.1371/journal.pgen.1005482

PGENETICS-D-15-01013 [pii]

Scaramozzino N, Sanz G, Crance JM, Saparbaev M, Drillien R, Laval J, Kavli B, and Garin D. 2003. Characterisation of the substrate specificity of homogeneous vaccinia virus uracil-DNA glycosylase. Nucleic Acids Res 31:4950-4957.

Sheng Z, Oka S, Tsuchimoto D, Abolhassani N, Nomaru H, Sakumi K, Yamada H, and Nakabeppu Y. 2012. 8Oxoguanine causes neurodegeneration during MUTYH-mediated DNA base excision repair. J Clin Invest 122:4344-4361. 65053 [pii]

10.1172/JCI65053

Silverstein TD, Johnson RE, Jain R, Prakash L, Prakash S, and Aggarwal AK. 2010. Structural basis for the suppression of skin cancers by DNA polymerase eta. Nature 465:1039-1043. nature09104 [pii]

10.1038/nature09104

Smith CA, and Taylor JS. 1993. Preparation and characterization of a set of deoxyoligonucleotide 49-mers containing site-specific cis-syn, trans-syn-I, (6-4), and Dewar photoproducts of thymidylyl(3'-->5')thymidine. J Biol Chem 268:11143-11151.

Sun B, Latham KA, Dodson ML, and Lloyd RS. 1995. Studies on the catalytic mechanism of five DNA glycosylases. Probing for enzyme-DNA imino intermediates. J Biol Chem 270:19501-19508.

Talhaoui I, Couve S, Gros L, Ishchenko AA, Matkarimov B, and Saparbaev MK. 2014. Aberrant repair initiated by mismatch-specific thymine-DNA glycosylases provides a mechanism for the mutational bias observed in CpG islands. Nucleic Acids Res 42:6300-6313. gku246 [pii]

10.1093/nar/gku246

Talhaoui I, Matkarimov BT, Tchenio T, Zharkov DO, and Saparbaev MK. 2017. Aberrant base excision repair pathway of oxidatively damaged DNA: Implications for degenerative diseases. Free Radic Biol Med 107:266-277. S0891-5849(16)31074-7 [pii]

10.1016/j.freeradbiomed.2016.11.040

Tchou J, Kasai H, Shibutani S, Chung MH, Laval J, Grollman AP, and Nishimura S. 1991. 8-oxoguanine (8hydroxyguanine) DNA glycosylase and its substrate specificity. Proc Natl Acad Sci U S A 88:4690-4694.

Tsai-Wu JJ, Liu HF, and Lu AL. 1992. Escherichia coli MutY protein has both N-glycosylase and apurinic/apyrimidinic endonuclease activities on A.C and A.G mispairs. Proc Natl Acad Sci US A 89:8779-8783.

Vasquez-Del Carpio R, Silverstein TD, Lone S, Johnson RE, Prakash L, Prakash S, and Aggarwal AK. 2011. Role of human DNA polymerase kappa in extension opposite from a cis-syn thymine dimer. J Mol Biol 408:252261. S0022-2836(11)00199-9 [pii]

10.1016/j.jmb.2011.02.042

Vassylyev DG, Kashiwagi T, Mikami Y, Ariyoshi M, Iwai S, Ohtsuka E, and Morikawa K. 1995. Atomic model of a pyrimidine dimer excision repair enzyme complexed with a DNA substrate: structural basis for damaged DNA recognition. Cell 83:773-782.

Vrouwe MG, Pines A, Overmeer RM, Hanada K, and Mullenders LH. 2011. UV-induced photolesions elicit ATRkinase-dependent signaling in non-cycling cells through nucleotide excision repair-dependent and independent pathways. J Cell Sci 124:435-446. jcs.075325 [pii]

$10.1242 /$ jcs.075325

Wang L, Chakravarthy S, and Verdine GL. 2017. Structural Basis for the Lesion-scanning Mechanism of the MutY DNA Glycosylase. J Biol Chem 292:5007-5017. M116.757039 [pii]

10.1074/jbc.M116.757039

Wang L, Lee SJ, and Verdine GL. 2015. Structural basis for avoidance of promutagenic DNA repair by MutY adenine DNA glycosylase. J Biol Chem 290:17096-17105. M115.657866 [pii] 
10.1074/jbc.M115.657866

Yanofsky C, Cox EC, and Horn V. 1966. The unusual mutagenic specificity of an E. coli mutator gene. Proc Natl Acad Sci USA 55:274-281.

Zharkov DO, Gilboa R, Yagil I, Kycia JH, Gerchman SE, Shoham G, and Grollman AP. 2000. Role for lysine 142 in the excision of adenine from A:G mispairs by MutY DNA glycosylase of Escherichia coli. Biochemistry 39:14768-14778. bi001538k [pii]

728

729

730

731

732

\section{FIGURE LEGENDS}

733

734

735

Figure 1. Analysis of the cleavage products generated by T4-PDG and UVDE enzymes when

736 acting upon 5'-[ $\left.{ }^{32} \mathrm{P}\right]$-labelled 24 mer duplex oligonucleotides containing CPD (denoted as T=T) and 6-4PP (denoted as T-T) adducts and 30 mer containing only CPD. Note that 24 and 30 mer oligonucleotides have different sequence contexts. For details, see Materials and Methods. Lanes 1, 7 and 10, control non-treated oligonucleotides; lanes 2-3 and 8-9, 24 mer AA $\bullet T=T$ and AA $\bullet$ T duplexes incubated either with T4-PDG or UVDE; lanes 11 and 12, 30 mer AA $\bullet T=T$ duplex incubated with T4-PDG and UVDE, respectively; lanes 4-6, 24 mer regular AA•TT duplex incubated with MtbXth, a 3'-5' exonuclease, to generate size markers.

743

Figure 2. Analysis of the cleavage products generated by MutY and UNG when acting upon 24 mer oligonucleotides containing base modifications. The $5^{\prime}-\left[{ }^{32} \mathrm{P}\right]-$ labelled 24 mer duplex oligonucleotides containing CPD, 6-4PP, mismatches A•G and A•80xoG and single-stranded 24 mer oligonucleotide containing uracil were incubated with MutY and UNG, respectively. Lanes 1-10, 24 mer duplexes incubated or not with MutY; lanes 11-14, 24 mer single-stranded oligonucleotides containing single Uracil residue, incubated or not with Ung to generate size markers. For details see Materials and Methods.

751

752

Figure 3. Analysis of the cleavage products generated by MutY when acting upon $5^{\prime}-\left[{ }^{32} \mathrm{P}\right]-$ labelled 30 and 24 mer duplex oligonucleotides containing either $A \cdot G$ mismatch or CPD adduct. Lanes 1, 3 and 5, control non-treated 30 mer oligonucleotides; lanes 2, 4 and 6, 30 mer duplexes incubated with MutY; Lanes 7, 9 and 11, control non-treated 24 mer duplexes; lanes 8, 10 and 12, 24 mer duplexes incubated with MutY. For details see Materials and Methods. 
758 Figure 4. Graphic representation of the UV-induced increase in mutation frequencies in E. coli 759 cells. NER-proficient strains were exposed to dose $100-180 \mathrm{~J} \cdot \mathrm{m}^{-2} \mathrm{UV}$ and NER deficient strains 760 to doses $10 \mathrm{~J} \cdot \mathrm{m}^{-2} \mathrm{UV}$, only. Data from at least 3 experiments were used for statistical analysis.

761

762 Figure 5. Graphic representation of the UV-induced increase in mutation frequencies in E. coli 763 strains containing the WT and D138N mutant MutY protein. NER-proficient AB1157 strain was 764 exposed to $100 \mathrm{~J} \cdot \mathrm{m}^{-2} \mathrm{UV}$ and NER deficient strains to only $10 \mathrm{~J} \cdot \mathrm{m}^{-2} \mathrm{UV}$. Data from at least 3 experiments were used for statistical analysis.

Figure 6. Distance between $\mathrm{Cl}^{\prime}$ atoms in the adjacent nucleotides. (A) Graphical representation of the interatomic distances. In 1TTD, 1COC, and 355D structures, all distances (except within a CPD in 1TTD) were measured as representative of B-DNA. MutY 5' and MutY 3', the distances from $\mathrm{Cl}^{\prime}$ of oxoG to $\mathrm{Cl}^{\prime}$ ' of $5^{\prime}$ - and 3'-adjacent nucleotides, respectively (structures 1RRQ, 1RRS, 1VRL, 3FSP, 5DPK, 3G0Q, 4YOQ, 4YPH, and 4YPR). CPD, the distance between two C1' atoms within a CPD (structures 1N4E, 1SKS, 1SL1, 1SL2, 1TTD, 1VAS, 3MFI, 3MR3, 3MR5, 773 3MR6, 3PZP, 3SI8, 4A0A, 4A0B, 4A08, 4A09, and 5B24). (B) Close view of a CPD in two 774 representative CPD-containing structures (1TTD: free CPD-containing DNA, 1VAS: CPD775 containing DNA from a complex with phage T4 endonuclease V) and a structure of the non776 target strand from a complex with G. stearothermophilus MutY (1RRQ). In the 1RRQ structure,

777 the wedging Tyr88 residue is shown. $\mathrm{Cl}^{\prime}-\mathrm{C} 1$ ' distances are indicated. 
779 Zutterling, C., ... "Aberrant repair initiated by the adenine-DNA glycosylase does not play a role

780 in UV-induced mutagenesis in Escherichia coli."

781

782 Supplemental Information

783

784 Supplementary Figure Legends

785

786

Figure S1. Analysis of the cleavage products generated by MutY when acting upon 5'-[32P]-

787 labelled 24 and 30 mer duplex oligonucleotides containing the $\mathrm{G} \bullet \mathrm{T}$ mismatch and CPD adduct.

788 Lanes $1,3,5,7,9,11,13,15$ and 17, control non-treated 24 and 30 mer duplex oligonucleotides; lanes $2,4,6,8,10,12,14,16$ and 18, 24 and 30 mer duplex oligonucleotides incubated with MutY. For details see materials and Methods.

791

792

Figure S2. Cleavage of the UV-irradiated pBlueScript SK $(+)$ plasmid DNA by DNA repair 793 enzymes. (A) Agarose gel electrophoresis ( $0.8 \%$ ) of the cleavage products generated by MutY, APE1 and T4 PDG when acting upon supercoiled (ccc) form of plasmid DNA. Lane 1, GeneRuler 1 kb DNA ladder; lanes 2-6, control non-treated plasmid DNA; lanes 7-11, UVirradiated plasmid DNA. The arrows denote the position of "ccc", "oc" and "lds" forms of plasmid DNA. For details see Materials and Methods. (B) Graphical representation of data from panel A.

\section{Supplementary Tables}

802

803 Supplementary Table S1. Structures used to calculate distance between $\mathrm{Cl}^{\prime}$ atoms in the 804 adjacent nucleotides 


\section{Figure 1}

Analysis of the cleavage products generated by T4-PDG and UVDE enzymes.

T4-PDG and UVDE enzymes were acted upon 5'-[ ${ }^{32}$ P]-labelled 24 and 30 mer duplex oligonucleotides containing CPD and 6-4PP adducts. Lanes 1, 7 and 10, control non-treated oligonucleotides; lanes 2-3 and 8-9, 24 mer AA $\cdot T=T$ and AA•T-T duplexes incubated either with T4-PDG or UVDE; lanes 11 and 12, 30 mer AA•T=T duplex incubated with T4-PDG and UVDE, respectively; lanes 4-6, 24 mer regular AA $-T$ duplex incubated with MtbXth, a 3'-5' exonuclease, to generate size markers. For details see materials and Methods.
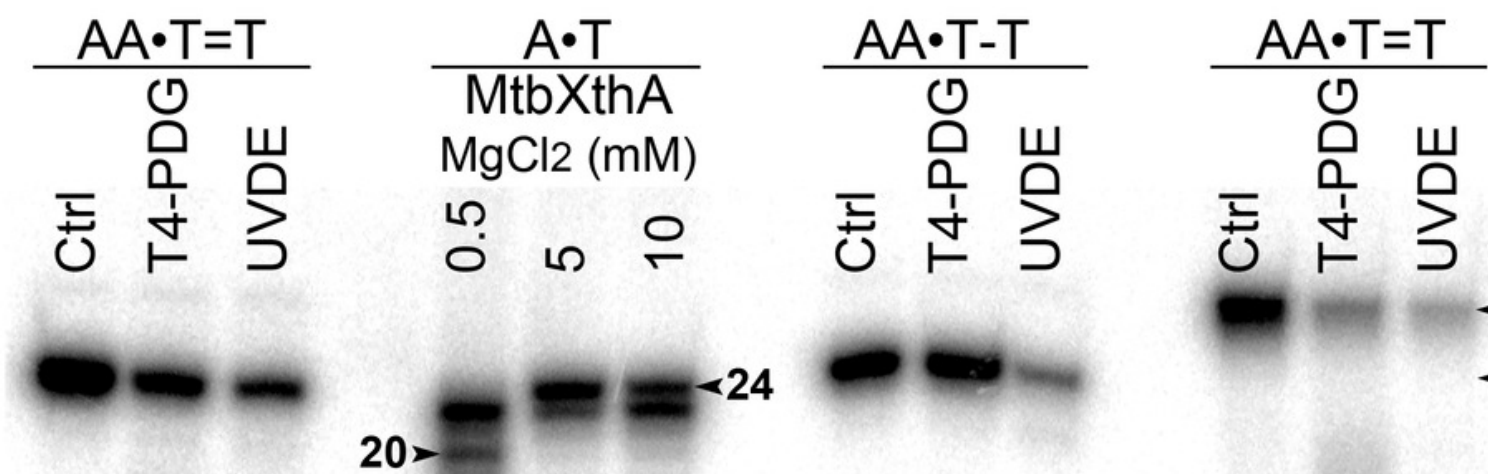

18>

$16^{-}$

14>

12-PUA 12- $\mathrm{OH}^{>}$
12>
$12-\mathrm{OH}$ <30mer

$<24$ mer

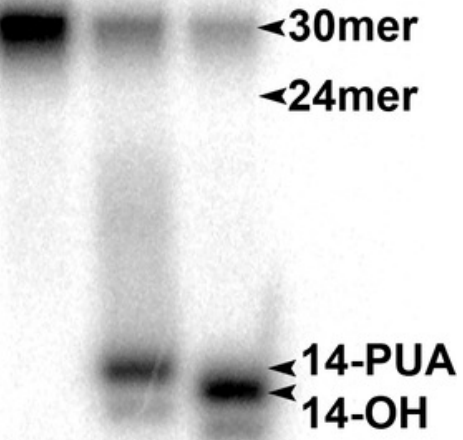

14-OH
456
$\begin{array}{lll}7 & 8 & 9\end{array}$
123 


\section{Figure 2}

Analysis of the cleavage products generated by MutY and UNG when acting upon 24 mer oligonucleotides containing base modifications.

The 5'-[ ${ }^{32} \mathrm{P}$ ]-labelled 24 mer duplex oligonucleotides containing CPD, 6-4PP, mismatches A•G and $A \cdot 80 \times 0 G$ and single-stranded 24 mer oligonucleotide containing uracil were incubated with MutY and UNG, respectively. Lanes 1-10, 24 mer duplexes incubated or not with MutY; lanes 11-14, 24 mer single-stranded oligonucleotides containing single Uracil residue, incubated or not with Ung to generate size markers. For details see Materials and Methods.
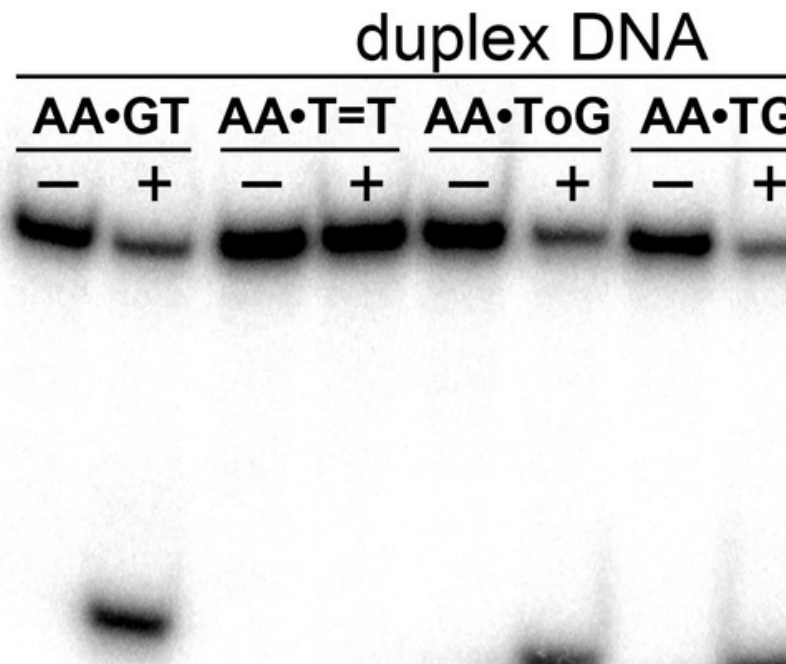

$\begin{array}{llllllll}1 & 2 & 3 & 4 & 5 & 6 & 7 & 8\end{array}$

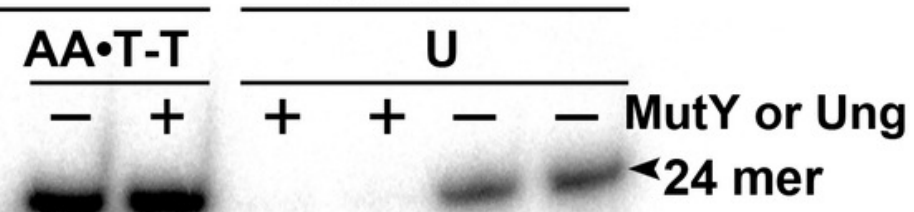

$\begin{array}{llllll}9 & 10 & 11 & 12 & 13 & 14\end{array}$ 


\section{Figure 3}

Analysis of the cleavage products generated by MutY when acting upon 30 and 24 mer duplex oligonucleotides containing either $A \bullet G$ mismatch or CPD adduct.

MutY was acted upon 5'-[ ${ }^{32}$ P]-labelled 30 and 24 mer duplex oligonucleotides containing either $A \bullet G$ mismatch or CPD adduct. Lanes 1, 3 and 5, control non-treated 30 mer oligonucleotides; lanes 2, 4 and 6, 30 mer duplexes incubated with MutY; Lanes 7, 9 and 11, control non-treated 24 mer duplexes; lanes 8, 10 and 12, 24 mer duplexes incubated with MutY. For details see materials and Methods.

\section{0 mer}

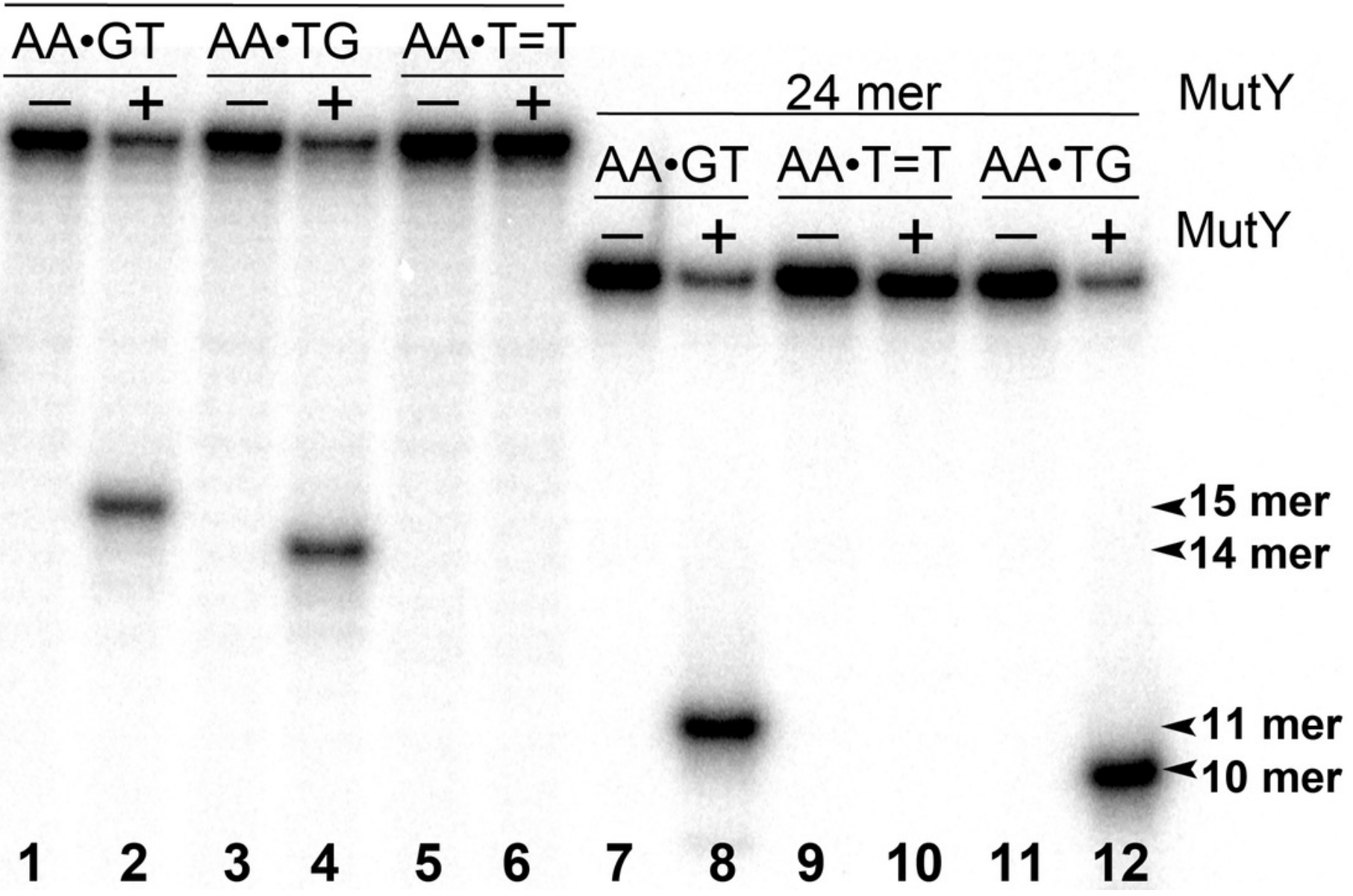




\section{Figure 4}

Graphic representation of the UV-induced increase in mutation frequencies in $E$. coli cells.

NER-proficient strains were exposed to dose $100-180 \mathrm{~J} \cdot \mathrm{m}^{-2}$ UV and NER deficient strains to doses $10 \mathrm{~J} \cdot \mathrm{m}^{-2} \mathrm{UV}$, only. Data from at least 3 experiments were used for statistical analysis. 


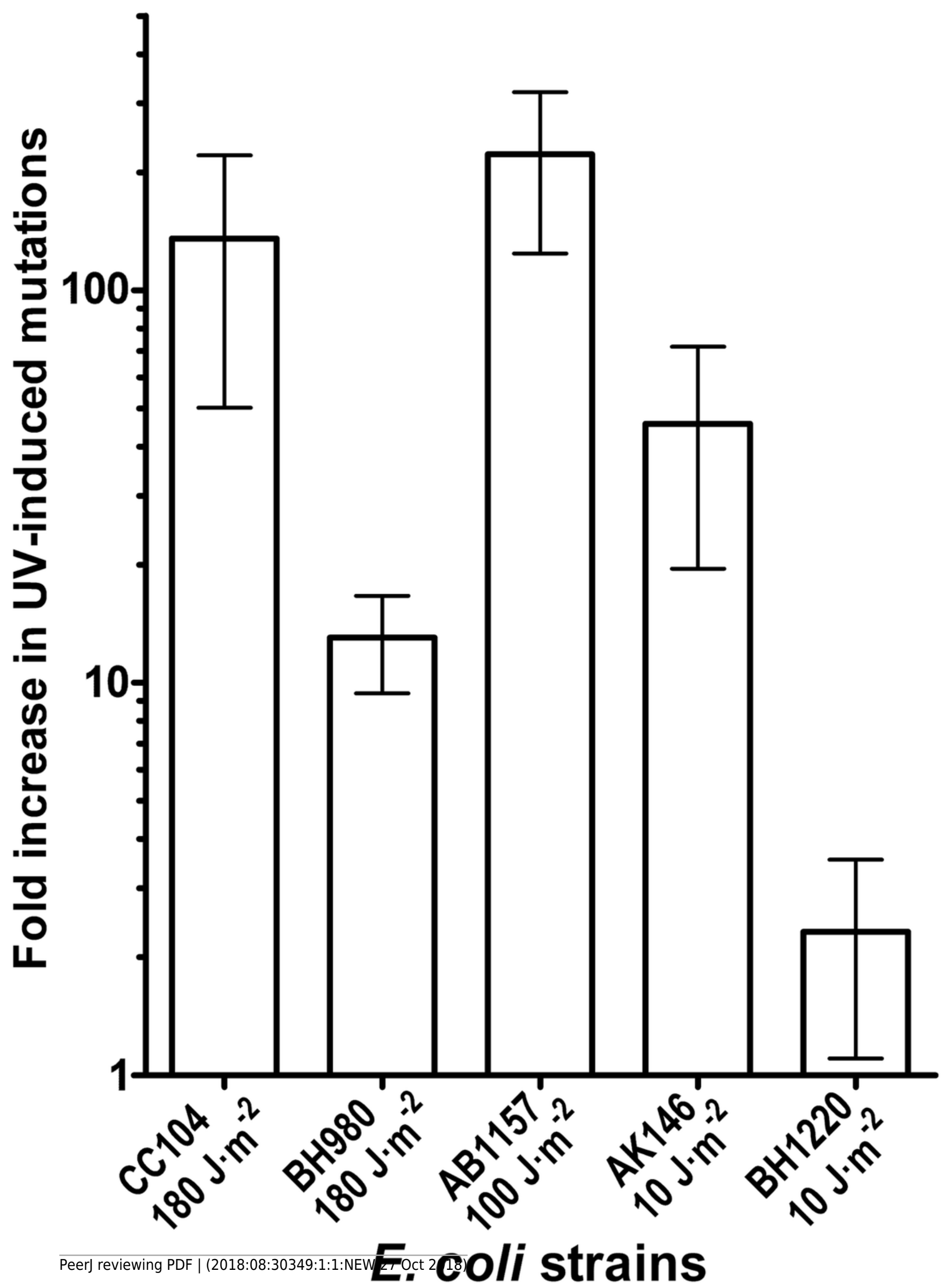


Figure 5

Graphic representation of the UV-induced increase in mutation frequencies in E. coli strains containing the WT and D138N mutant MutY protein.

NER-proficient AB1157 strain was exposed to $100 \mathrm{~J} \cdot \mathrm{m}^{-2} \mathrm{UV}$ and NER deficient strains to only $10 \mathrm{~J} \cdot \mathrm{m}^{-2}$ UV. Data from at least 3 experiments were used for statistical analysis. 


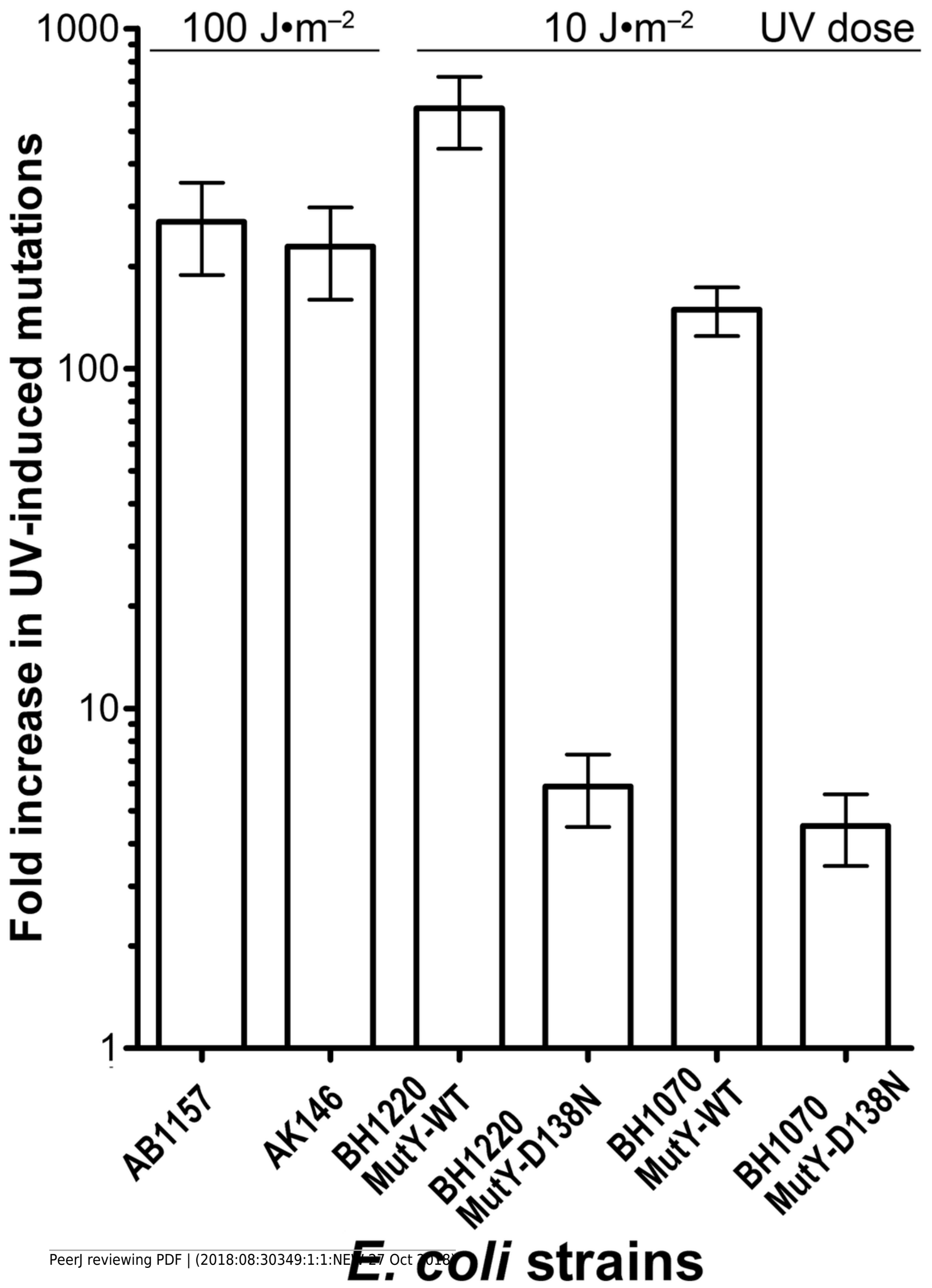




\section{Figure 6}

Distance between $\mathrm{Cl}^{\prime}$ atoms in the adjacent nucleotides.

( A ) Graphical representation of the interatomic distances. In 1TTD, 1COC, and 355D

structures, all distances (except within a CPD in 1TTD) were measured as representative of B-DNA. MutY $5^{\prime}$ and MutY $3^{\prime}$, the distances from $\mathrm{Cl}^{\prime}$ of oxoG to $\mathrm{Cl}^{\prime}$ of $5^{\prime}$ - and $3^{\prime}$-adjacent nucleotides, respectively (structures 1RRQ, 1RRS, 1VRL, 3FSP, 5DPK, 3G0Q, 4YOQ, 4YPH, and 4YPR). CPD, the distance between two $\mathrm{Cl}^{\prime}$ atoms within a CPD (structures 1N4E, 1SKS, 1SL1, 1SL2, 1TTD, 1VAS, 3MFI, 3MR3, 3MR5, 3MR6, 3PZP, 3SI8, 4A0A, 4A0B, 4A08, 4A09, and 5B24). ( $B$ ) Close view of a CPD in two representative CPD-containing structures (1TTD: free CPD-containing DNA, IVAS: CPD-containing DNA from a complex with phage T4 endonuclease $\mathrm{V}$ ) and a structure of the non-target strand from a complex with $G$. stearothermophilus MutY (1RRQ). In the 1RRQ structure, the wedging Tyr88 residue is shown. $\mathrm{Cl}^{\prime}-\mathrm{Cl}^{\prime}$ distances are indicated.

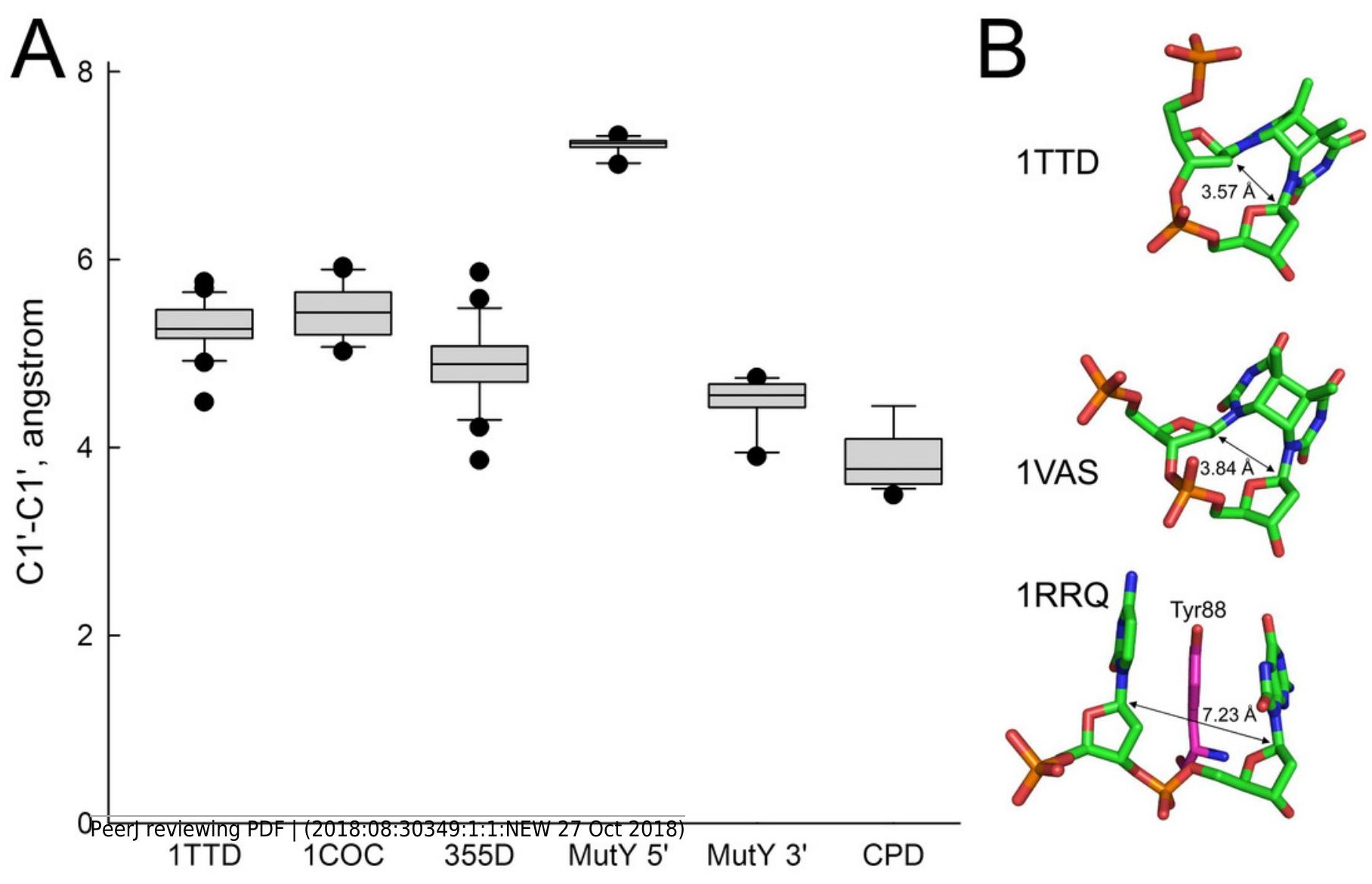




\section{Table $\mathbf{1}$ (on next page)}

Bacterial strains. 
2 Table 1. Bacterial strains.

\begin{tabular}{|c|c|c|}
\hline Strain & Genotype & Source of derivation \\
\hline $\mathrm{AB} 1157$ & $\begin{array}{l}\text { thr-1 leu-6 proA2 his-4 argE3 thi-1 lacYI } \\
\text { galK2 ara-14 xyl-5 mtl-1 tsx-33 rpsL31 } \\
\text { supE44 }\end{array}$ & laboratory stock \\
\hline BH200 & as $\mathrm{AB} 1157$ but $u v r A: \because \operatorname{Tn} 10$ & laboratory stock \\
\hline AK146 & as $\mathrm{AB} 1157$ but $u v r A 6$ & $\begin{array}{l}\text { A. Kuzminov (University of } \\
\text { Illinois, USA). }\end{array}$ \\
\hline BH1220 & as $\mathrm{AB} 1157$ but $u v r A 6$ mic $A:: K n^{R}$ & laboratory stock \\
\hline BH1070 & $\begin{array}{l}\text { as GC4468 } F^{-} \text {- lac4169 rpsL but uvrA6 } \\
m i c A:: K n^{R}\end{array}$ & laboratory stock \\
\hline $\mathrm{CC} 104$ & $\begin{array}{l}\mathrm{P} 90 \mathrm{C}\left[\operatorname{ara} \Delta(\text { lacproB })_{X I I I}\right] \text { carrying an } \\
F^{\prime} \text { lacI-Z }- \text { proB }{ }^{+} \text {episome }(\mathrm{G} \bullet \mathrm{C} \rightarrow \mathrm{T} \bullet \mathrm{A})\end{array}$ & $\begin{array}{l}\text { J.H. Miller (University of } \\
\text { California, USA). }\end{array}$ \\
\hline BH980 & as $\mathrm{CC} 104$ but $\operatorname{mic} A: \because K n^{R}$ & laboratory stock \\
\hline
\end{tabular}

3

4 


\section{Table 2 (on next page)}

Frequencies of UV induced $\mathrm{Rif}^{\mathrm{S}} \rightarrow \mathrm{Rif}^{\mathrm{R}}$ mutation in E. coli WT versus micA strains. 
1

2 Table 2. Frequencies of $U V$ induced $\mathrm{Rif}^{\mathrm{S}} \rightarrow \operatorname{Rif}^{\mathrm{R}}$ mutation in $E$. coli $W T$ versus mic $A$ strains.

\begin{tabular}{|c|c|c|c|c|c|c|c|c|c|}
\hline \multirow{2}{*}{\begin{tabular}{|l} 
E. coli strains \\
\end{tabular}} & \multirow[b]{2}{*}{$\begin{array}{l}\stackrel{\sim}{\tilde{I}} \\
\stackrel{\dot{0}}{0} \\
\dot{0} \\
\stackrel{0}{0}\end{array}$} & \multirow[b]{2}{*}{ 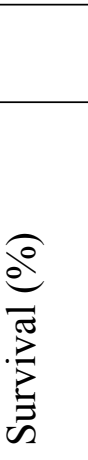 } & \multicolumn{2}{|c|}{ No UV } & \multicolumn{2}{|l|}{ UV } & \multirow{2}{*}{ 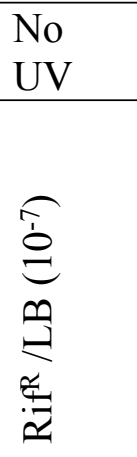 } & \multirow{2}{*}{ 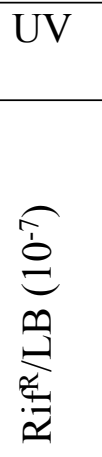 } & \multirow[b]{2}{*}{ 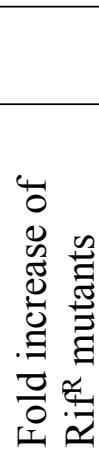 } \\
\hline & & & $\begin{array}{l}\vec{\Xi} \\
\overline{0} \\
\overline{0} \\
0 \\
\hat{0} \\
\overline{0} \\
\bar{\theta}\end{array}$ & $\frac{\vec{\Xi}}{\frac{\Xi}{\tilde{q}}}$ & 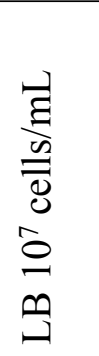 & 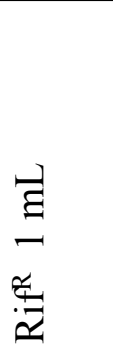 & & & \\
\hline CC104 $(W T)$ & $\begin{array}{c}180 \\
\mathrm{~J} \cdot \mathrm{m}^{-2}\end{array}$ & 5.1 & 3600 & 210 & 200 & 7670 & 0.058 & 3.73 & 64 \\
\hline $\begin{array}{c}\text { BH980 } \\
\left(m i c A:: K n^{R}\right)\end{array}$ & $\begin{array}{c}180 \\
\mathrm{~J} \cdot \mathrm{m}^{-2}\end{array}$ & 12.0 & 200 & 129 & 87 & 640 & 0.645 & 7.37 & 11.4 \\
\hline $\mathrm{AB} 1157(W T)$ & $\begin{array}{c}100 \\
\mathrm{~J} \cdot \mathrm{m}^{-2}\end{array}$ & 0.1 & 320 & 3,5 & 140 & 476 & 0,01 & 3,4 & 311 \\
\hline $\begin{array}{l}\text { AK146 } \\
(u v r A O)\end{array}$ & $\begin{array}{c}10 \\
\mathrm{~J} \cdot \mathrm{m}^{-2}\end{array}$ & 5.2 & 255 & 5 & 19,5 & 31 & 0,0196 & 1,59 & 81 \\
\hline $\begin{array}{c}\text { BH1220 } \\
(u v r A 6 \\
\left.m i c A:: K a n^{R}\right)\end{array}$ & $\begin{array}{c}10 \\
\mathrm{~J} \cdot \mathrm{m}^{-2}\end{array}$ & 1.0 & 300 & 246 & 35 & 112,5 & 0,82 & 3,21 & 3.9 \\
\hline
\end{tabular}

3

4 


\section{Table 3(on next page)}

Frequencies and molecular spectra of spontaneous and UV induced mutations in the $E$. coli MutY-proficient and MutY-deficient strains. 
2 Table 3. Frequencies and molecular spectra of spontaneous and UV induced mutations in the $E$.

3 coli MutY-proficient and MutY-deficient strains.

\begin{tabular}{|c|c|c|c|c|c|}
\hline E. coli strains & 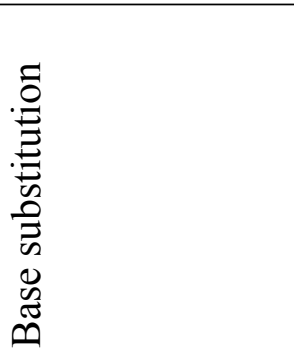 & 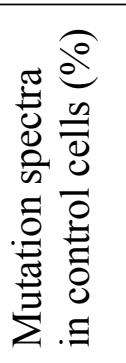 & 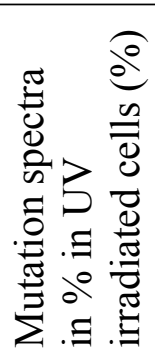 & 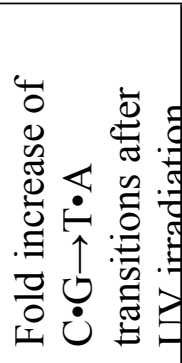 & 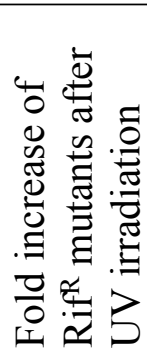 \\
\hline \multirow[t]{5}{*}{$\mathrm{AB} 1157(W T)$} & $\mathrm{C} \rightarrow \mathrm{T} \& \mathrm{G} \rightarrow \mathrm{A}$ & 12.6 & 81.3 & 768 & \multirow[t]{5}{*}{140} \\
\hline & $\mathrm{T} \rightarrow \mathrm{C} \& \mathrm{~A} \rightarrow \mathrm{G}$ & 38.4 & 3.1 & & \\
\hline & $\mathrm{A} \rightarrow \mathrm{C} \& \mathrm{~T} \rightarrow \mathrm{G}$ & 30.8 & - & & \\
\hline & $\mathrm{A} \rightarrow \mathrm{T} \& \mathrm{~T} \rightarrow \mathrm{A}$ & 7.6 & 12.5 & & \\
\hline & $\mathrm{G} \rightarrow \mathrm{T} \& \mathrm{C} \rightarrow \mathrm{A}$ & 3.8 & 3.1 & & \\
\hline \multirow[t]{4}{*}{$\mathrm{BH} 200(u v r A:: \operatorname{Tn} 10)$} & $\mathrm{C} \rightarrow \mathrm{T} \& \mathrm{G} \rightarrow \mathrm{A}$ & 40.0 & 92.0 & 224 & \multirow[t]{4}{*}{98} \\
\hline & $\mathrm{T} \rightarrow \mathrm{C} \& \mathrm{~A} \rightarrow \mathrm{G}$ & 20 & - & & \\
\hline & $\mathrm{A} \rightarrow \mathrm{T} \& \mathrm{~T} \rightarrow \mathrm{A}$ & 20 & - & & \\
\hline & $\mathrm{G} \rightarrow \mathrm{T} \& \mathrm{C} \rightarrow \mathrm{A}$ & - & 3.8 & & \\
\hline \multirow[t]{4}{*}{ AK146 (uvrA6) } & $\mathrm{C} \rightarrow \mathrm{T} \& \mathrm{G} \rightarrow \mathrm{A}$ & 60.0 & 75.0 & 218 & \multirow[t]{4}{*}{224} \\
\hline & $\mathrm{T} \rightarrow \mathrm{C} \& \mathrm{~A} \rightarrow \mathrm{G}$ & 15.0 & - & & \\
\hline & $\mathrm{G} \rightarrow \mathrm{T} \& \mathrm{C} \rightarrow \mathrm{A}$ & 15.0 & 12.5 & & \\
\hline & $\mathrm{A} \rightarrow \mathrm{T} \& \mathrm{~T} \rightarrow \mathrm{A}$ & 10.0 & 12.5 & & \\
\hline \multirow{2}{*}{$\begin{array}{c}\text { BH1220 }(u v r A 6 \\
\left.m i c A: K a n^{R}\right)\end{array}$} & $\mathrm{C} \rightarrow \mathrm{T} \& \mathrm{G} \rightarrow \mathrm{A}$ & 6.5 & 63.6 & 86 & \multirow[t]{2}{*}{3.9} \\
\hline & $\mathrm{G} \rightarrow \mathrm{T} \& \mathrm{C} \rightarrow \mathrm{A}$ & 84.0 & 27.3 & & \\
\hline \multirow{2}{*}{$\begin{array}{c}\text { BH1070 }(u v r A 6 \\
\left.m i c A:: K a n^{R}\right)\end{array}$} & $\mathrm{C} \rightarrow \mathrm{T} \& \mathrm{G} \rightarrow \mathrm{A}$ & 2.6 & 76.2 & 239 & \multirow[t]{2}{*}{4.5} \\
\hline & $\mathrm{G} \rightarrow \mathrm{T} \& \mathrm{C} \rightarrow \mathrm{A}$ & 87.2 & 7.1 & & \\
\hline
\end{tabular}

